\title{
Evaluation of Polar MM5 Simulations of Antarctic Atmospheric Circulation*
}

\author{
Zhichang GuO AND David H. BRomwich \\ Polar Meteorology Group, Byrd Polar Research Center, and Atmospheric Sciences Program, Department of Geography, \\ The Ohio State University, Columbus, Ohio \\ JOHN J. CASSANO + \\ Polar Meterology Group, Byrd Polar Research Center, The Ohio State University, Columbus, Ohio
}

(Manuscript received 23 May 2001, in final form 5 August 2002)

\begin{abstract}
Evaluation of a complete annual cycle of nonhydrostatic mesoscale model simulations of the Antarctic atmospheric circulation is presented. The year-long time series are compiled from a series of overlapping shortduration $(72 \mathrm{~h}$ ) simulations of the atmospheric state with the first $24 \mathrm{~h}$ being discarded for spinup reasons, and the 24-72-h periods used for model evaluation. The simulations are generated with the fifth-generation Pennsylvania State University-National Center for Atmospheric Research Mesoscale Model (MM5), which is modified for polar applications, and is referred to as the Polar MM5. With a horizontal resolution of $60 \mathrm{~km}$, the Polar MM5 has been run for the period of January 1993-December 1993, creating short-term simulations from initial and boundary conditions provided by the European Centre for Medium-Range Weather Forecasts (ECMWF) Tropical Ocean Global Atmosphere (TOGA) operational analyses. The model output is compared with observations from automatic weather stations, upper-air data, and global atmospheric analyses as well as climatological maps over timescales from diurnal to annual. In comparison with the observations, the evaluation shows that simulations with the Polar MM5 capture both the large- and regional-scale circulation features with generally small bias in the modeled variables. For example, the differences between the observations and simulations at the 500-hPa level are usually less than $2^{\circ} \mathrm{C}$ for temperature and dewpoint temperature, and $20 \mathrm{~m}$ for geopotential height. On the annual timescale the largest errors in the model simulations are the deficient total cloud cover and precipitation, and the colder near-surface temperature over the interior of the Antarctic plateau. The deficiencies in the cloud prediction and precipitation simulation follow from low-level dry biases found in the Polar MM5 simulations, and the cold bias is related to the low predicted downward longwave radiation under clear skies in the radiation parameterization scheme. The deficient predicted precipitation also reflects the limited ability of Polar MM5 to represent clear sky precipitation. On the seasonal timescale a persistent positive pressure bias is found in the model simulations, caused by the interaction between the gravity waves and the model upper boundary condition. The observed synoptic variability of the pressure, temperature, wind speed, wind direction, and water vapor mixing ratio, as well as the diurnal cycles of temperature, wind speed, and mixing ratio, are reproduced by the Polar MM5 with reasonable accuracy.
\end{abstract}

\section{Introduction}

In the last decade, many advances have been achieved in improving the numerical simulations of Antarctic atmospheric circulation. First, the quality of global atmospheric analysis products over the Southern Ocean has improved significantly in recent years and this is reflected by the parallel improvements noted in the fore-

\footnotetext{
* Byrd Polar Research Center Contribution Number 1241.

+ Current affiliation: CIRES, University of Colorado, Boulder, Colorado.
}

Corresponding author address: David H. Bromwich, Polar Meteorology Group, Byrd Polar Research Center, The Ohio State University, 1090 Carmack Rd., Columbus, OH 43210.

E-mail: bromwich@polarmet1.mps.ohio-state.edu cast and simulation fields (Turner et al. 1999). Additionally, more observational data available from the rapid expansion of automatic weather stations (AWSs) across the Antarctic continent (e.g., Stearns et al. 1993) have allowed for the refinement and tuning of numerical models. Second, as more powerful supercomputers have become available, the horizontal resolution in global climate model (GCM) studies has increased. With the increased resolution (and better parameterizations) recent GCM simulations of Antarctic climate (e.g., Tzeng et al. 1994; Chen et al. 1995; Briegleb and Bromwich 1998a,b) have improved considerably in relation to previous versions (Simmonds 1990; Xu et al. 1990). At the same time, high-resolution mesoscale models and regional climate system models have been used in the study of Antarctic atmospheric circulation (e.g., Hines et al. 1995, 1997b; Walsh and McGregor 1996; van 
Lipzig et al. 1999; Bailey and Lynch 2000a,b). Their results have shown smaller errors than comparable global simulations. Finally, the observational and diagnostic investigations of Antarctic weather systems (Carleton and Song 1997), boundary layer structure (Heinemann and Rose 1990; King 1990; Cassano et al. 2001b), and mesoscale disturbances formed in the coastal region (Turner and Thomas 1994; Carrasco et al. 1997a,b) also have improved our understanding of Antarctic atmospheric circulation. These advances are reflected in the selection of more appropriate physical parameterization schemes and associated parameters, and in the realistic representation of the sea ice extent as well as the associated energy fluxes between the Southern Ocean and the atmosphere.

Despite the advances achieved in the last decade, the simulations produced for the Antarctic are still not as accurate as those prepared for lower latitudes (Turner et al. 1996). The shortage of observations, the nature of the complex atmospheric flow over the extended glacial plateau and steeply sloping coastal margins, and the extensive area of sea ice present major obstacles to the production of realistic simulations of Antarctic atmospheric circulation and accurate forecasts of the associated meteorological elements. The expanding field operations in the Antarctic demand accurate short-range numerical weather forecasts. For this purpose, one regional atmospheric mesoscale model, Polar MM5, adapted specifically for the Antarctic environment from the fifth-generation Pennsylvania State University-National Center for Atmospheric Research (PSU-NCAR) Mesoscale Model (MM5; Grell et al. 1994), is being used at two locations to produce real-time mesoscale and synoptic forecasts in the Antarctic (model output is available on the World Wide Web at http://www-bprc. mps.ohio-state.edu/ANWP and http://www.mmm.ucar. edu/rt/mm5/amps). So far, few efforts have been made to produce detailed model verification statistics specifically for the Antarctic. In order to assess the model performance for the Antarctic region and identify areas for model improvement, this paper presents an evaluation of model simulations over the Antarctic using Polar MM5. Section 2 summarizes the modifications to the standard MM5 that are required to make it suitable for ice sheet environments in general, and Antarctica in particular.

The Polar MM5 has been run for the period of January 1993-December 1993 in a complete annual series of short-term simulations from initial and boundary conditions provided by the operational analyses of the European Centre for Medium-Range Weather Forecasts (ECMWF). This 12-month period, when the average precipitation is close to the annual average for 198595 (Cullather et al. 1998), was selected to provide a test of the model performance over an entire annual cycle. Cassano et al. (2001a) and Bromwich et al. (2001) have done a similar verification of this model in simulating Greenland's atmospheric circulation. Because Antarc- tica has a much more extensive area of elevated glacial ice and unique meteorological conditions (e.g., King and Turner 1997; Bromwich and Parish 1998), we concentrate here on the performance of this model in simulating Antarctic atmospheric circulation.

In section 3, the observational data from AWS and manned sites are described. The model skill, primarily in relation to observations from AWS sites and climatological charts, is evaluated in section 4 on annual, seasonal, synoptic, and diurnal timescales. Concluding remarks on the model performance and areas requiring additional model improvements are given in section 5 .

\section{Polar MM5}

The Polar MM5 model is based on version 2.9 of the PSU-NCAR MM5. A general description of version 2 of MM5 is given by Dudhia (1993) and Grell et al. (1994). A detailed discussion of the modifications made to the standard version of MM5 for use over polar regions is described in Bromwich et al. (2001) and Cassano et al. (2001a). A brief description of Polar MM5 and its configuration for simulations over Antarctica is presented in this section.

\section{a. Polar MM5 dynamics and physics}

The simulations presented in this paper were conducted with the Polar MM5 with the use of nonhydrostatic dynamics. The nonhydrostatic version of the model includes three-dimensional prognostic equations for the horizontal and vertical components of the wind, temperature, and pressure perturbation, which refers to a prescribed pressure reference state. Additionally, threedimensional prognostic equations for the water vapor, cloud water (ice), and rainwater (snow) mixing ratios are also part of the model equations. Parameterizations for moist physics, radiative transfer, and turbulence are included in the model, with multiple options available for the representation of many of these processes.

For the Polar MM5 simulations, moist physics are simulated with explicit cloud and precipitation prediction schemes. The Reisner explicit microphysics parameterization (Reisner et al. 1998) is used to represent the resolvable-scale cloud and precipitation processes, and the Grell parameterization (Grell et al. 1994) is used to represent the subgrid-scale cloud processes. Results from MM5 (MM4) sensitivity simulations show that excessive cloud cover was found to be a problem over the Antarctic and for cold, high clouds over the continental United States (Hines et al. 1997a,b; Manning and Davis 1997). It was found that the use of the Fletcher (1962) equation in the microphysics parameterization scheme results in an unrealistically small size and large values of the number concentration of simulated ice crystals at very low air temperatures, and is highly unfavorable for the conversion of clouds to precipitation. In order to eliminate this cloudy bias in polar simula- 
tions with MM5 the equation for ice nuclei concentration from Meyers et al. (1992) was used to replace the Fletcher (1962) equation in the explicit microphysics parameterization, as suggested by Manning and Davis (1997). This modification to the Reisner microphysics parameterization is used for all of the simulations presented here.

The radiative transfer of shortwave and longwave radiation through the atmosphere is predicted with a modified version of the NCAR Community Climate Model, version 2 (CCM2), radiation parameterization (Hack et al. 1993). The CCM2 parameterization scheme represents the optical properties of the cloud particles (liquid water droplets and ice crystals) in terms of the cloud water path. In its original version, the cloud cover was predicted as a simple function of the grid-box relative humidity, and only the cloud liquid water (CLW) path determined from the grid-box temperature was accounted for in the cloud radiative properties. Sensitivity simulations revealed that this parameterization of cloud cover tended to significantly overestimate the CLW path and, thus, resulted in particularly large downwelling longwave radiation fluxes during the austral winter over the Antarctic ice sheet (Hines et al. 1997a,b). For the Polar MM5 simulations, the cloud ice water (CIW) path and its radiative effects are included in the modified CCM2 radiation parameterization to represent the radiative properties of ice cloud species. In order to resolve the problem addressed above, the predicted cloud water and ice mixing ratios from the Reisner explicit microphysics parameterization are used to determine CLW and CIW path, and radiative properties of the modeled cloud cover. This modification is similar to that in the CCM3 radiation parameterization (Kiehl et al. 1996), which is in part based on the results of Ebert and Curry (1992). The modified radiation scheme allows for a consistent treatment of the radiative and microphysical properties of the clouds and for the separate treatment of the radiative properties of liquid and ice phase cloud particles.

Turbulent fluxes in the atmosphere, and the turbulent fluxes between the atmosphere and the surface, are parameterized using the 1.5 -order turbulence closure parameterization used in the National Centers for Environmental Prediction Eta Model (Janjić 1994). Heat transfer through the model substrate is predicted using a multilayer "soil" model. The thermal properties used in the soil model for snow and ice surface types are modified following Yen (1981). In addition the number of substrate levels represented in the soil model is increased from six to eight, with an increase in the resolved substrate depth from 0.47 to $1.91 \mathrm{~m}$. Also, a sea ice surface type is added to the 13 surface types available in the standard version of MM5 (Hines et al. 1997b). The sea ice surface type allows for fractional sea ice cover at any oceanic grid point, with surface fluxes at the sea ice grid points calculated separately for the open water and sea ice portions of the grid point.
TABLE 1. List of surface characteristics for the surface types of interest in this study.

\begin{tabular}{lcc}
\hline \hline $\begin{array}{l}\text { Surface } \\
\text { type }\end{array}$ & Albedo & \multicolumn{1}{c}{ Roughness length $(\mathrm{m})$} \\
\hline Ice sheet & 0.80 & $1 \times 10^{-2}$ \\
Sea ice & 0.70 & $1 \times 10^{-3}$ \\
Ocean & 0.15 & Minimum $1 \times 10^{-4}$ with Charnock relation \\
\hline
\end{tabular}

These fluxes are then averaged before interacting with the overlying atmosphere. The sea ice thickness varies from 0.2 to $0.95 \mathrm{~m}$ and is dependent on the hemisphere and sea ice fraction at the grid point. Some surface characteristics for the surface types of interest in this study are listed in Table 1.

\section{b. Model grid and topography}

MM5 is formulated using a staggered horizontal grid with a vertical terrain-following $\sigma$-coordinate system. The square model domain used in this study consists of 120 grid points in each orthogonal direction, centered at the South Pole, with a horizontal polar stereographic projection resolution of $60 \mathrm{~km}$ (Fig. 1). The model topography data over the Antarctic continent are interpolated from a $5-\mathrm{km}$ resolution digital elevation model of Antarctica (Liu et al. 1999) using bilinear interpolation from the nearest points, and the 1-2-1 smoother, which is one option for model topography smoothing provided in the standard MM5 package, has been used. The areas for the Filchner-Ronne Ice Shelf and the Ross Ice Shelf are manually identified from climatic maps. The surface height and land use type for both ice shelves are set to $50 \mathrm{~m}$ and permanent ice, respectively. The nonhydrostatic $\sigma$ levels are defined with respect to a reference pressure profile, $p_{0}(z)$, according to

$$
\sigma(x, y, z)=\frac{p_{0}(z)-p_{\text {top }}}{p_{s 0}(x, y)-p_{\text {top }}},
$$

where $p_{\text {top }}$ is the reference pressure at the model top, and it is set at a constant pressure of $100 \mathrm{hPa}$, and a radiative condition is used at the upper boundary (Klemp and Durran 1983). A total of $28 \sigma$ levels are used, of which 7 are located within the lowest $400 \mathrm{~m}$ of the atmosphere. The lowest sigma level is located at a nominal height of $11 \mathrm{~m}$ above ground level (AGL). This relatively high resolution near the surface is required to accurately represent the evolution of the shallow katabatic layer over the Antarctic ice sheet. The surface reference pressure is $p_{s 0}$ (a function of the model terrain field). Because $\sigma$ depends only on the reference state $p_{0}$ and the model terrain field, the heights of the model levels do not vary with time. Total pressure is defined according to

$$
p(x, y, z, t)=p_{0}(z)+p^{\prime}(x, y, z, t),
$$

where $p^{\prime}$ is the prognostic perturbation pressure variable. 


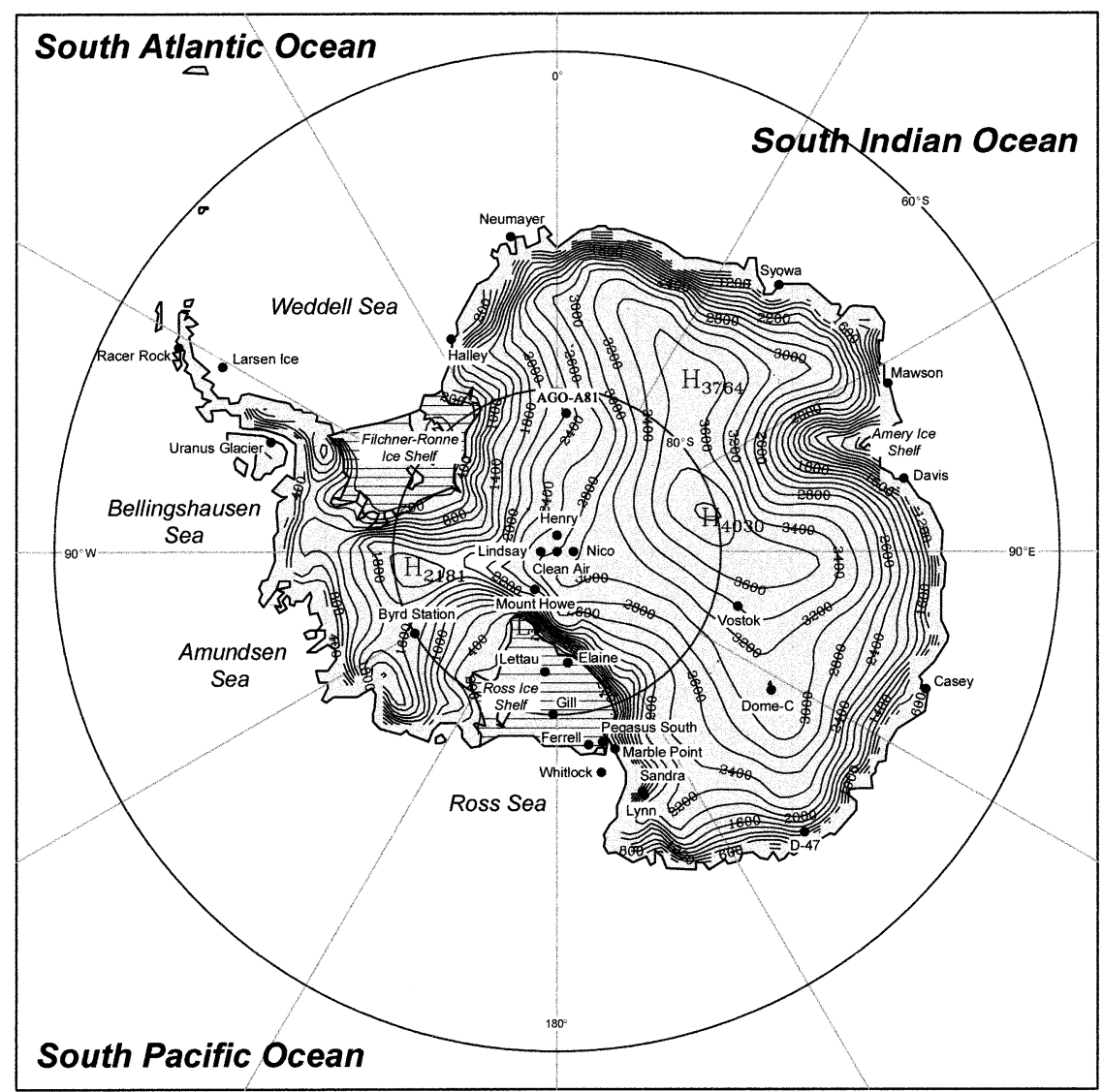

FIG. 1. Polar MM5 model domain and terrain. Elevation contour interval is $200 \mathrm{~m}$.

\section{c. Polar MM5 initial and boundary condition data}

The datasets used to initialize the Polar MM5 and to provide boundary conditions to the model during the simulations are listed in Table 2 . The $2.5^{\circ}$ horizontal resolution ECMWF Tropical Ocean Global Atmosphere (TOGA) surface and upper-air operational analyses are used to provide the initial and boundary conditions for the model atmosphere. These data are interpolated to the Polar MM5 model grid using the standard preprocessing programs provided by NCAR for use with the MM5 modeling system. In addition the $1.125^{\circ}$ ECMWF TOGA global surface analyses are used to specify the initial surface temperature (and sea surface temperature) and deep soil temperature. Due to the treatment of the ice shelves as sea ice, large warm near-surface temperature biases $\left(>10^{\circ} \mathrm{C}\right)$ have been noted in the ECMWF data over these features (e.g., Renfrew et al. 2002). As indicated in figures to be presented, this does not appear to have a significant effect on the Polar MM5 simulated near-surface temperatures over the ice shelves that are treated as continental ice in Polar MM5. The daily polar gridded sea ice concentration data with $25-\mathrm{km}$ horizontal resolution obtained from the National Snow and Ice Data Center are used to identify the sea ice surface type and its fractional coverage.

The Polar MM5 is used to produce short-duration (72$\mathrm{h}$ length) simulations of the atmospheric state over Antarctica from January through December 1993. The model is initialized with the 0000 UTC ECMWF analyses for each preceding even day or the 31 st of the preceding month for each simulation, with the 24-72-h intervals used for model verification. The 72-h integration strategy is used in the simulations because it demands less computation and data storage than the 48-h simulation

TABLE 2. List of datasets and initial settings used for Polar MM5 simulations.

\begin{tabular}{lc}
\hline \hline & Input data \\
\hline Initial and boundary condition atmospheric data & 12-hourly 2.5 ECMWF TOGA global analyses \\
Topography & Liu et al. (1999), 5-km resolution \\
Sea surface temperature & 6-hourly 1.125 ECMWF TOGA global surface analyses \\
Sea ice coverage & DMSP SSM/I daily polar gridded sea ice concentration data \\
\hline
\end{tabular}




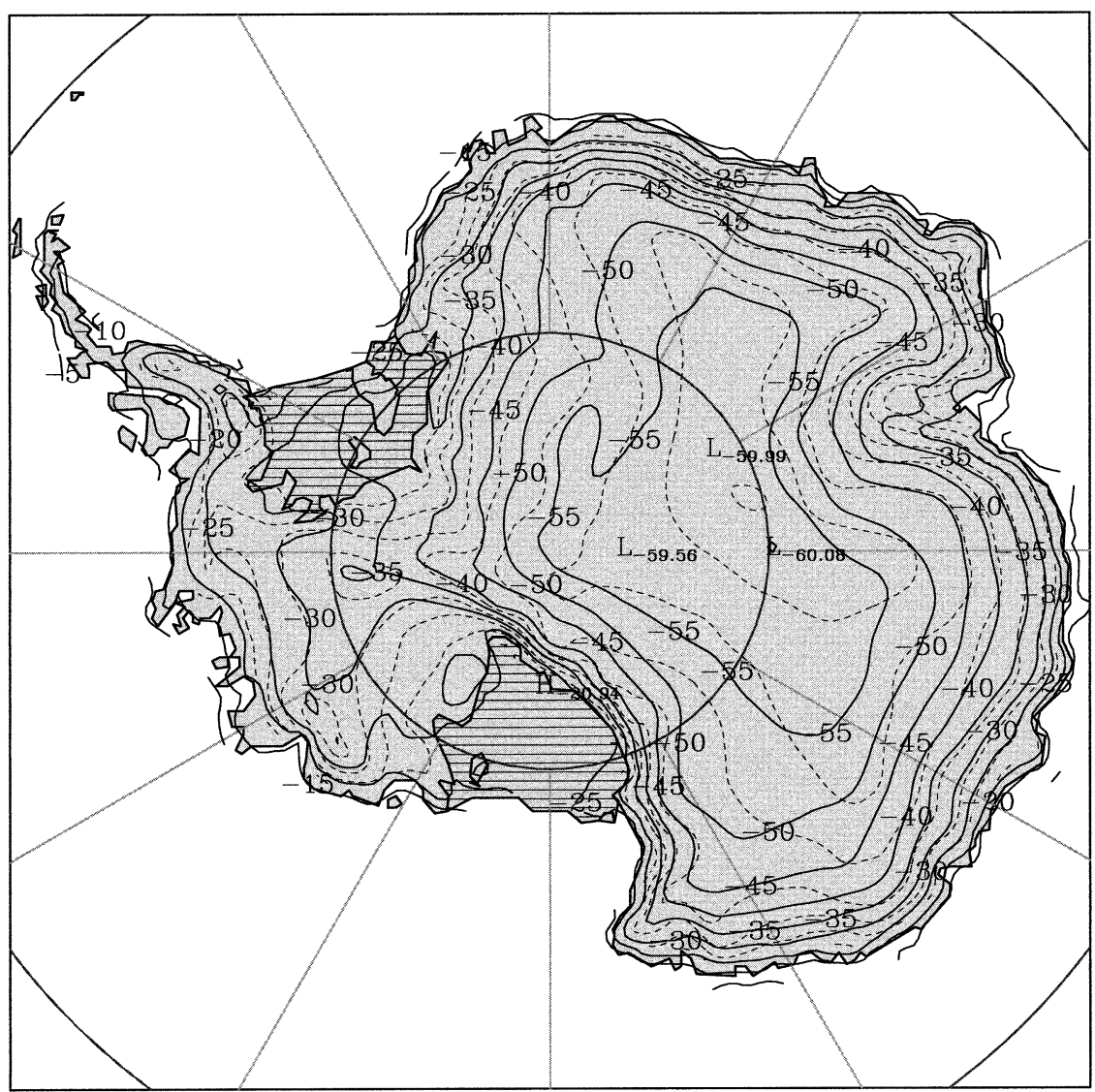

FIG. 2. Annual mean surface air temperature $\left({ }^{\circ} \mathrm{C}\right)$ in 1993 simulated by Polar MM5. Dashed lines are elevation contours in 500-m increments.

approach used previously (e.g., Cassano et al. 2001a), and it is still valid for model evaluation although the degree of simulation degradation is larger than for the 48-h simulations.

\section{AWS and manned station data}

The primary data source used for verification of the Polar MM5 simulations presented in this paper are observations from the University of Wisconsin automatic weather stations (UW-AWS; online at ftp://ice.ssec. wisc.edu/pub/antrdr) and the manned stations over Antarctica. The UW-AWSs are funded by the National Science Foundation's Office of Polar Programs to support meteorological research and operations. During the model verification period (January-December 1993) 40 AWS sites and 10 manned stations were operational although many of them have incomplete records. The observation data from Antarctic manned stations as part of the World Meteorological Organization (WMO) network are available at the Web site of the British Antarctic Survey (http://www.antarctica.ac.uk/ met/metlog/).

The variables (air temperature, wind speed, wind direction, and relative humidity), which will be used for model verification, are measured at both the UW-AWS and the Antarctic manned stations. The AWS basic units measure air temperature, wind speed, wind direction, and relative humidity at a nominal height of $3 \mathrm{~m}$ above the surface (Holmes et al. 1993), and measure the air pressure at the height of the electronics enclosure. The UW-AWS data are collected by the Argos Data Collection System on board the National Oceanic and Atmospheric Administration series of polar-orbiting satellites. Based on the record completeness, reliability, and location representation, 28 stations (21 AWS sites and 7 manned stations; see Fig. 1 for locations) are selected from the AWS and manned stations mentioned above.

The temperature and wind speed simulated by the Polar MM5 are interpolated from the model lowest level (nominal $11 \mathrm{~m} \mathrm{AGL)}$ to a constant height of $3 \mathrm{~m} \mathrm{AGL}$ for comparison with the AWS measurements. This interpolation is done by applying Monin-Obukhov similarity theory (Stull 1988) to the temperature and wind speed at the lowest model level, the model surface temperature, and the model-specified surface roughness length. In applying this interpolation the diabatic correction term from Monin-Obukhov similarity theory is neglected. The model surface pressure has also been 


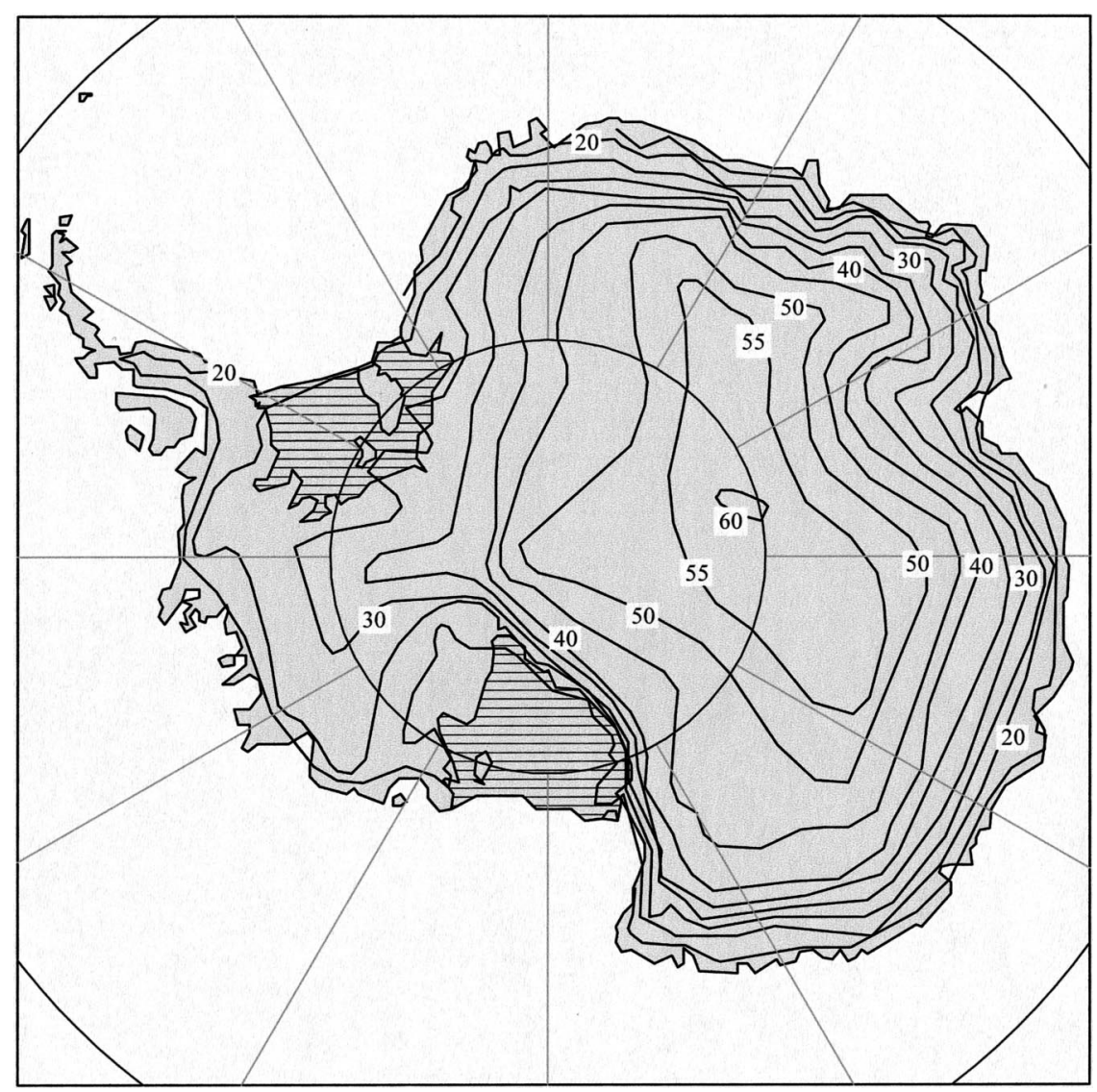

FIG. 3. Average annual near-surface temperature field synthesized from surface observations. Isotherms are in degrees below $0^{\circ} \mathrm{C}$. [After Giovinetto et al. (1990).]

adjusted from the model gridpoint elevation to the elevation of the AWS observation, using the hypsometric equation. All other model output is not modified prior to comparison with the AWS and manned station observations.

\section{Evaluation of Polar MM5 simulations}

Model output from the Polar MM5 (hereinafter PMM5) simulations over Antarctica is compared to available observational data on annual, seasonal, synoptic, and diurnal timescales in the following sections. This evaluation is intended to demonstrate the skill present in the PMM5 simulations over the range of timescales of interest for operational numerical weather prediction through seasonal- and climate-scale simulations. This analysis also serves to highlight areas requiring additional model improvements.

\section{a. Annual and seasonal means}

Annual mean fields from the PMM5 simulations are calculated for the surface temperature, near-surface winds, total cloud cover, and accumulated precipitation minus sublimation $(P-E)$, and winter mean fields are calculated for the near-surface temperature inversion and near-surface winds. These model fields are compared with available observations in the discussion below. The variables that were selected for comparison are important elements of the Antarctic climate. The selected variables allow for a characterization of the modeled near-surface state, and $P-E$ is important for studies of the ice sheet mass balance. The selection of observational maps is reasonable given that few choices are available for comparison.

Evaluation of the modeled annual near-surface air temperature field (Fig. 2) is conducted using the synthesis of observational data given by Giovinetto et al. (1990), reproduced in Fig. 3. In Fig. 2 the mean annual near-surface temperature in 1993 simulated by PMM5 is shown. Comparing these two maps, two slight differences exist. First, areas enclosed within the $-50^{\circ}$ and $-55^{\circ} \mathrm{C}$ contour lines in the simulated field are larger than those shown by Giovinetto et al. and the simulated temperatures are colder than the climatologically depicted annual surface temperature in the enclosed areas. Second, the location of the high plateau minimum temperature is a little farther east in the model air temperature. Differences between the observed and modeled mean annual surface temperature are caused by the un- 


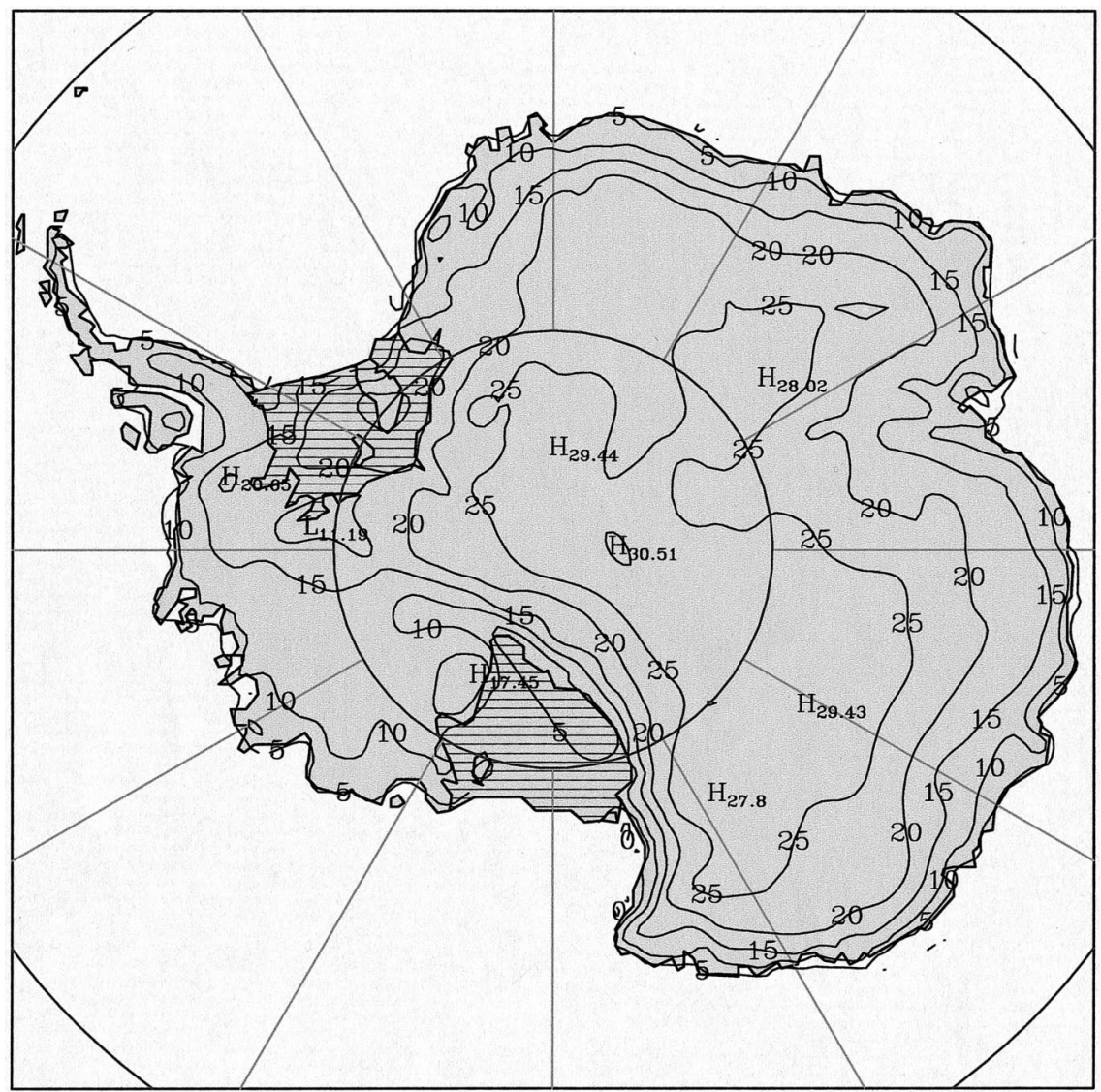

FIG. 4. Polar MM5 surface temperature inversion strength $\left({ }^{\circ} \mathrm{C}\right)$ in winter (JJA) 1993.

derestimation of CLW and CIW path as well as the deficit in downward longwave radiation from the modified CCM2 radiation parameterization scheme under clear skies (Pinto and Curry 1997). The low-level dry biases found in the PMM5 simulations (discussed below) are the main causes of the underestimation of CLW and CIW path and the related deficiency of the simulated total cloud cover and precipitation over the interior of the Antarctic plateau. The interannual variability, which is not represented in the single annual cycle simulated by the PMM5, may also add to these differences or act to mask errors between the climatological fields and the $1 \mathrm{yr}$ of model output. In this study, the year 1993 is chosen since it is close to the climatological state based on the average precipitation estimation (Cullather et al. 1998). Apart from these discrepancies, close fidelity between the simulated and observed temperature fields can be found for both distribution and magnitude. The coldest mean annual temperature on both maps is about $-60^{\circ} \mathrm{C}$, located near the highest elevation of the ice sheet in a region of minimum cloud cover. In addition the temperature gradients along the East Antarctic escarpment are reproduced quite well in the simulated field. There is also a clear representation of the Antarctic Peninsula and West Antarctic plateau in the temperature field. As will be shown below, the model reproduces the annual cycle of temperature with reasonable accuracy at a large number of AWS and manned sites located on the Antarctic ice sheet, lending further credence to the distribution of the mean annual temperature simulated by the PMM5.

Another variable related to the temperature is the near-surface inversion strength. Figures 4 and 5 show the mean winter (averaged over June, July, and August) near-surface temperature inversion simulated by PMM5 and derived from surface data with radiosonde data calibration, respectively; this is calculated as the difference between maximum temperature within the lowest 1000 $\mathrm{m}$ AGL and the near-surface temperature. The distribution and magnitude of simulated winter surface temperature inversion in Fig. 4 is similar to that given by Phillpot and Zillman (1970) in Fig. 5, and the model captures the intensity and horizontal structure of the inversion over Antarctica. However, the areas with average inversion strength exceeding $20^{\circ}$ and $25^{\circ} \mathrm{C}$ in PMM5 simulations are larger than those given by Phillpot and Zillman (1970). This difference is in part caused by the colder near surface temperature simulated by PMM5. It also should be noted that the winter inversion strength on the Antarctic high plateau, as determined 


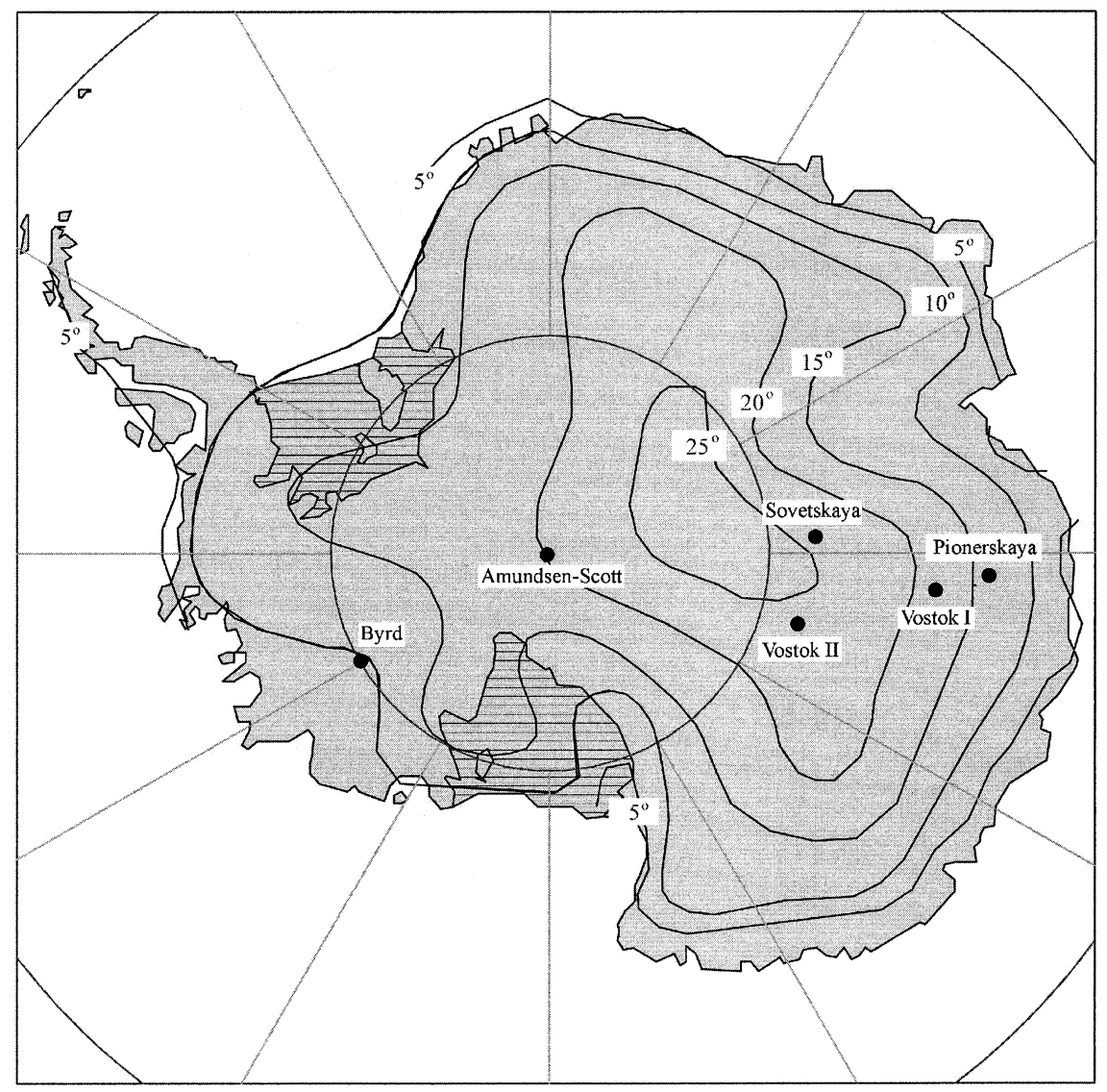

FIG. 5. Isopleths of the average strength $\left({ }^{\circ} \mathrm{C}\right)$ of the surface temperature inversion over the Antarctic continent in winter (JJA). [After Phillpot and Zillman (1970).] Dots show the observation sites used for compilation in the interior of Antarctica.

by Phillpot and Zillman (1970), is based on only a few point measurements at the stations shown in Fig. 5.

The PMM5 annual resultant wind streamlines from the lowest model level (approximately $11 \mathrm{~m} \mathrm{AGL)} \mathrm{are}$ shown in Fig. 6. A detailed streamline pattern obtained from simulations with the diagnostic planetary boundary layer model of Ball (1960) using a horizontal resolution of $50 \mathrm{~km}$ by Parish and Bromwich (1987) is displayed in Fig. 7. PMM5 clearly produces the continent-scale drainage flow seen in Fig. 7 over East Antarctica as cold low-level air flows from the high plateau to the sea. The drainage flow over the ice sheet is directed downslope and to the left of the ice fall line (Fig. 6 ), as expected for katabatic flow in the Southern Hemisphere. The PMM5 simulations also capture the fine details of the near-coastal convergence zones seen in Fig. 7. The winter resultant wind directions and wind speed contours derived from the PMM5 simulations and Parish and Bromwich (1991) simulations are shown in Figs. 8 and 9, respectively. In Parish and Bromwich (1991), the near-surface winds are simulated with the Parish and Waight (1987) mesoscale model under idealized, and clear sky wintertime, conditions, and wind speeds are vertical average values for the first $125 \mathrm{~m}$
AGL. In Figs. 8 and 9, the barrier winds along the east side of the southern half of the Antarctic Peninsula are well captured by the simulations; their absence farther north in Fig. 8 probably results in part from the topographic smoothing of the $60-\mathrm{km}$ model resolution. The PMM5 simulated winter resultant winds, particularly the locations of wind speed maxima and minima (Fig. 8), are similar to the Parish and Bromwich (1991) simulations. The weakest resultant wind speeds are located along the ice divide, with stronger flow over the steep coastal slopes (Fig. 8), where the most persistent katabatic flow is likely to be. The primary difference between the simulations is the weaker wind speeds simulated by the PMM5 than that given by Parish and Bromwich (1991). This difference arises from two sources. First, Parish and Bromwich's result represents a vertical average for the first $125 \mathrm{~m} \mathrm{AGL}$ rather than the $11 \mathrm{~m}$ AGL value simulated by PMM5. Second, the Parish and Bromwich result represents a mature katabatic episode rather than the spectrum of events averaged by PMM5.

The mean annual total cloud cover derived from the cloud optical depth using PMM5 explicit microphysics simulation of CLW and CIW path (Kiehl et al. 1996) 


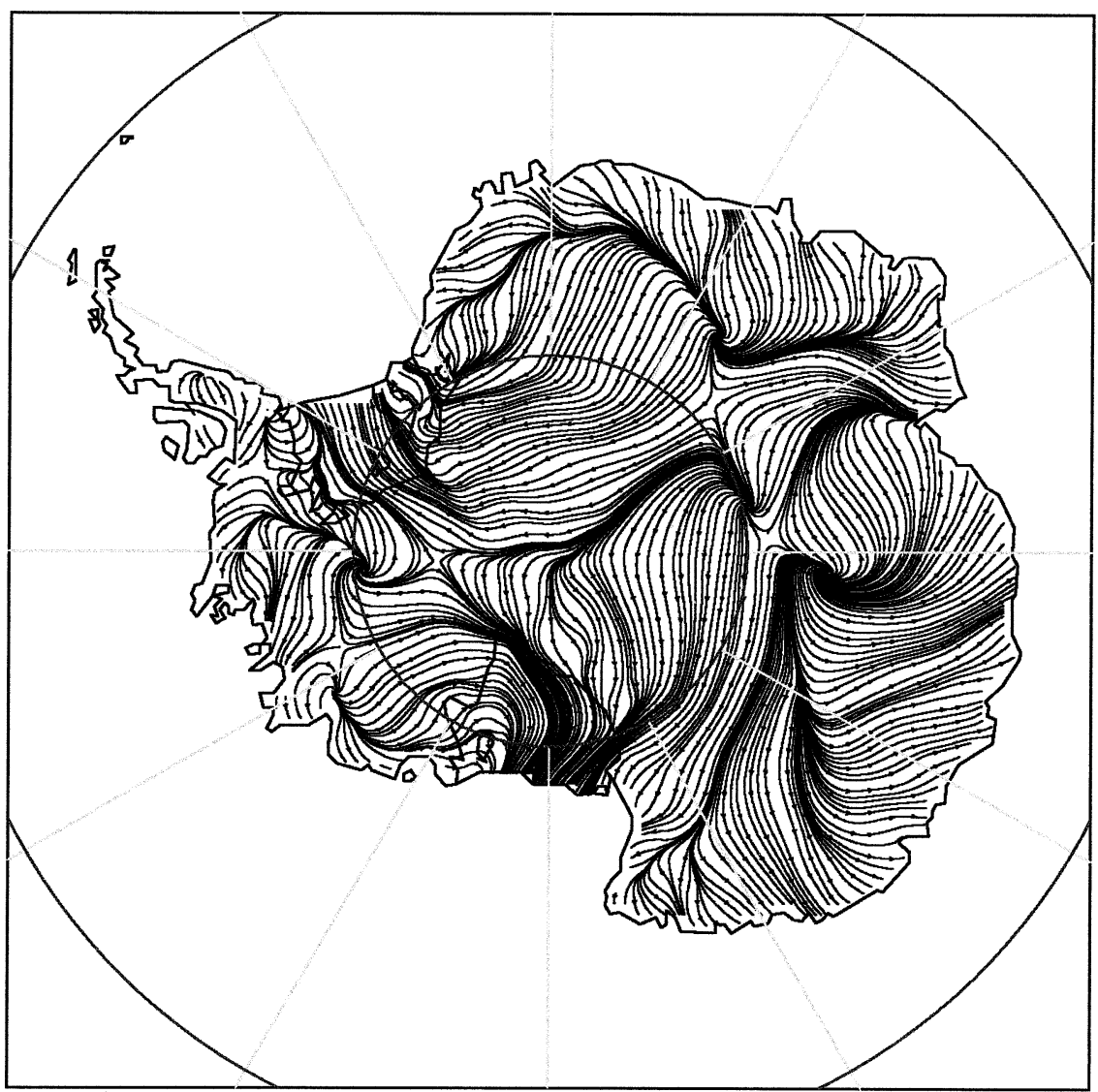

FIG. 6. Streamlines of annual resultant near-surface winds over Antarctica simulated by Polar MM5.

and compiled from climatological station observations (Borisenkov and Dolganov 1982) is shown in Figs. 10 and 11 , respectively. The total cloud cover over the Antarctic plateau in the PMM5 simulation is uniformly less than Borisenkov and Dolganov's compilation. In Table 3, the mean annual and seasonal total cloud cover for eight manned stations is compared to the PMM5 output. The deficient mean annual total cloud cover over the continental interior estimated from the PMM5 output and demonstrated in Figs. 10 and 11 is also confirmed by the observations from South Pole and Vostok stations. The negative bias is present at all of the stations over the annual mean, and is most pronounced in the spring (SON) and summer (DJF) months. The model appears to predict clouds with the greatest skill in the autumn (MAM) and winter (JJA) months. No marked spatial trends are evident when comparing the biases at various stations; they appear to be somewhat fixed in absolute amount. In a relative sense, however, the bias has a much greater impact in the interior because of smaller cloud fractions. The undersimulation of cloud cover is likely caused by the low-level dry biases found in the PMM5 simulations (based on South Pole radiosonde data, not shown), and the method used to determine cloud cover from PMM5 output. First, the deficient moisture content (dry bias) directly reduces the formation of different species of clouds. Second, the total cloud cover in PMM5 simulations is based on the cloud optical depth calculated from the simulated cloud liquid water and cloud ice water path. The very cold temperatures in the interior of the continent lead to very small values of liquid water and ice path, and result in small values of the calculated optical depth and cloud cover. One other possible source of the large PMM5 cloud cover biases that occur in the spring and summer months (especially over the interior) may be related to changes in the circulation induced by ozone depletion; these changes are only weakly captured in the PMM5 simulations due to the problems near the model top (described below). Neff (1999) attributes an increase of $15 \%-20 \%$ in spring and summer cloud fraction at South Pole over the last four decades to changes in the circulation induced by ozone depletion. By contrast, the underobservation of cloud cover due to observations taken during the polar night (Hahn et al. 1995) may be partially responsible for the smaller biases in the PMM5 cloud cover in autumn and winter. At the South Pole, Hahn et al. (their Fig. 13b) estimate that clouds are underestimated by $0.5-1.0$ tenths during autumn and winter. The authors do not find this for the spring months 


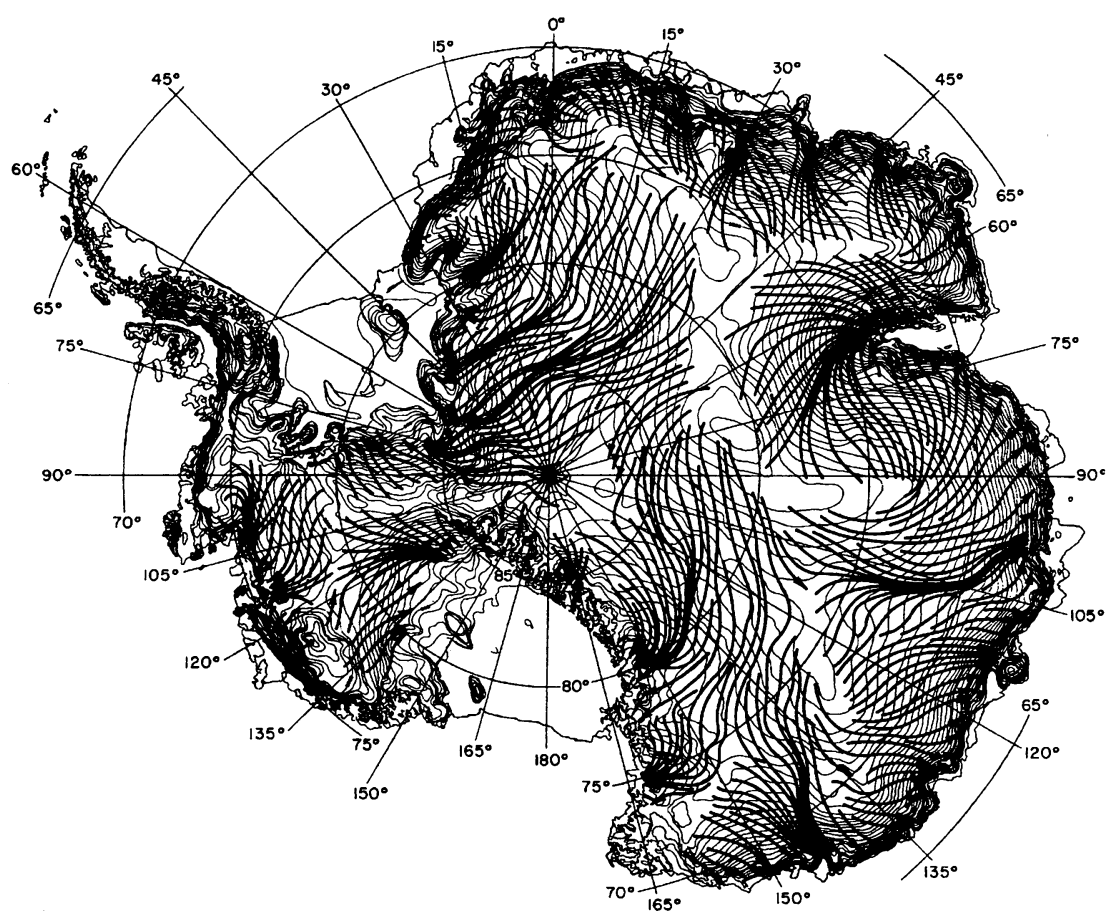

FIG. 7. Simulated streamlines of time-averaged surface winds over Antarctica (heavy lines) from Parish and Bromwich (1987). Thin lines are elevation contours in 100-m increments.

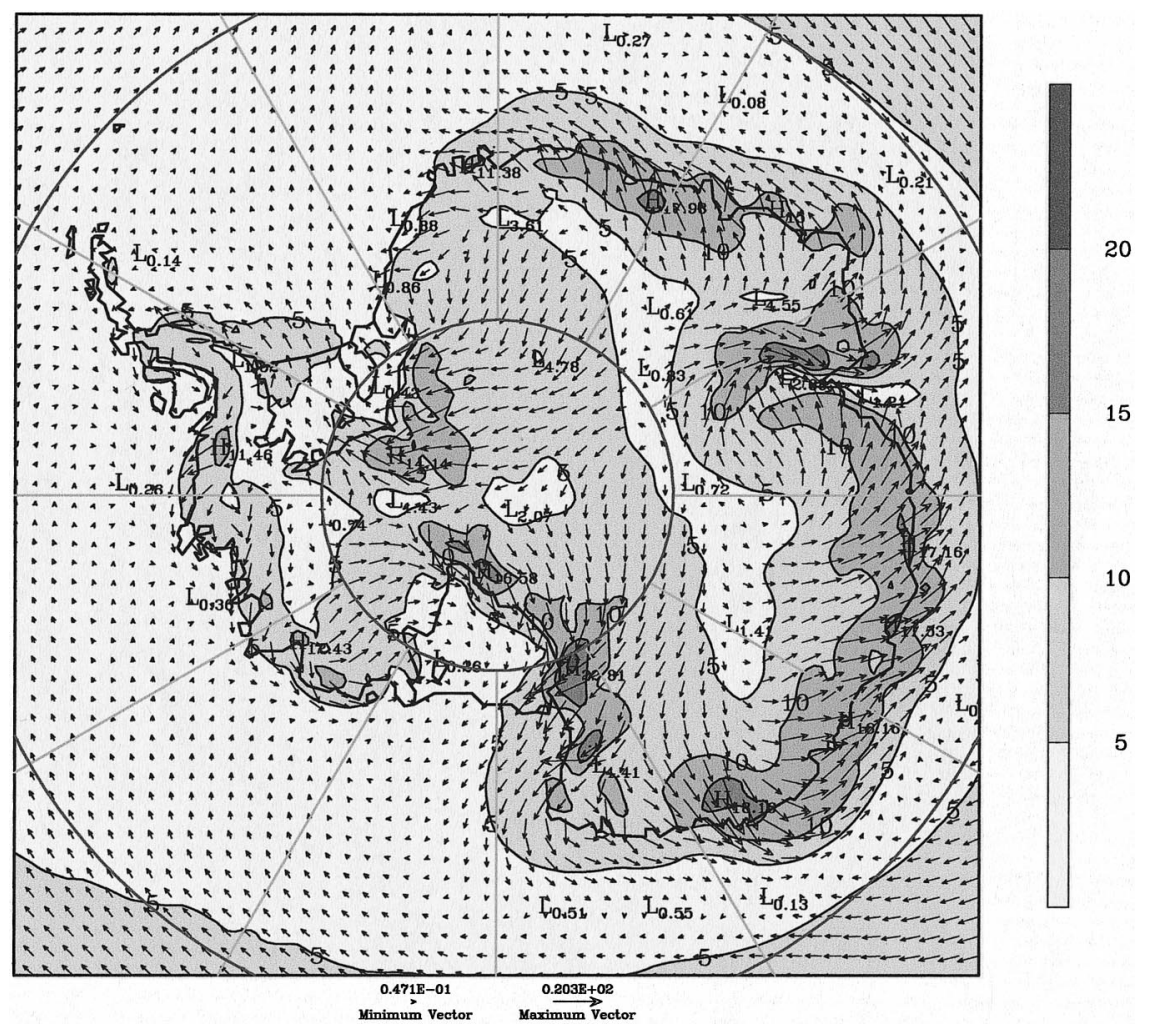

FIG. 8. Resultant near-surface wind fields in winter (JJA) 1993 simulated by Polar MM5 (units, $\mathrm{m} \mathrm{s}^{-1}$ ). 


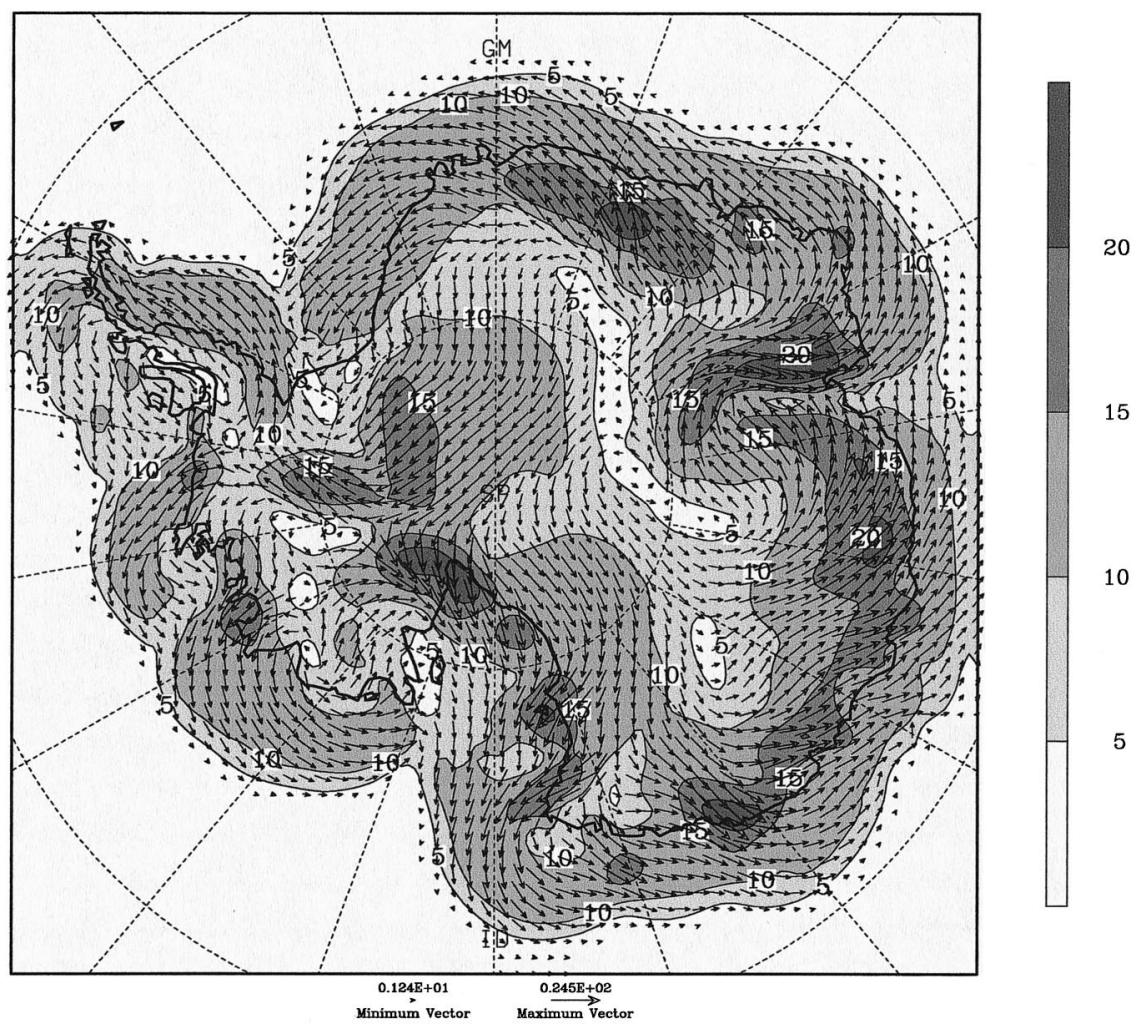

FIG. 9. Near-surface winds (units, $\mathrm{m} \mathrm{s}^{-1}$ ) for winter reproduced from Parish and Bromwich (1991).

at South Pole, which is consistent with the large biases in the PMM5 cloud cover during spring. Despite these possible sources of difference between the two datasets, there is a high degree of similarity. Both figures confirm that the zone covering the Southern Ocean near $60^{\circ} \mathrm{S}$ is the cloudiest place in the Southern Hemisphere, with more than $90 \%$ cloud cover. Also it is found in both figures that the amount of cloud over the continent decreases rapidly inland from the coast, and the least cloud cover is located over the highest surface elevations.

Figure 12 shows the annual precipitation minus sublimation in 1993 simulated by the PMM5. Sublimation is derived from the simulated latent heat flux. Compared to the accumulation analysis of Vaughan et al. (1999) from surface observations in Fig. 13, most major features are captured. These include the large values along the coast of East and West Antarctica, and over the Antarctic Peninsula, and the small amounts over the plateau of East Antarctica and around the Ross, Amery, and Ronne Ice Shelves. In general the model predicted $P-E$ distribution is in good qualitative agreement with the analysis of Vaughan et al. (1999), with the greatest differences located in the interior of the Antarctic continent. In the interior of the Antarctic continent the $P$ - $E$ values are significantly smaller than the analysis of Vaughan et al. (1999). The mean annual sublimation field is very close to that estimated by van den Broeke
(1997), and the time series of the precipitation events over all interior sites appears to be episodic (not shown). Thus, this difference reflects the limited ability of PMM5 in representing clear sky precipitation, which is continuously formed in the interior of Antarctica without any organized synoptic-scale process, and composes a large fraction of the total precipitation (Bromwich 1988). In addition, the deficient cloud prediction from the PMM5 also contributes to the underestimated precipitation. Interannual variability is another possible cause of the difference in estimates.

\section{b. Seasonal cycle}

The model verification on the seasonal timescale using observations from the UW-AWS array and manned stations is presented in this section. Monthly mean values of surface pressure, temperature, wind speed, wind direction, and mixing ratio are averaged over 28 AWS and manned sites (Fig. 1) and the corresponding model grid points in the PMM5. An observation site and the corresponding model gridpoint value are included during averaging only if both data are available. These monthly means are plotted in Fig. 14. The monthly bias, root-mean-square error (rmse), and correlation coefficient calculated from 3-hourly values and averaged over the same 28 sites as in Fig. 14 are shown in Fig. 15. 


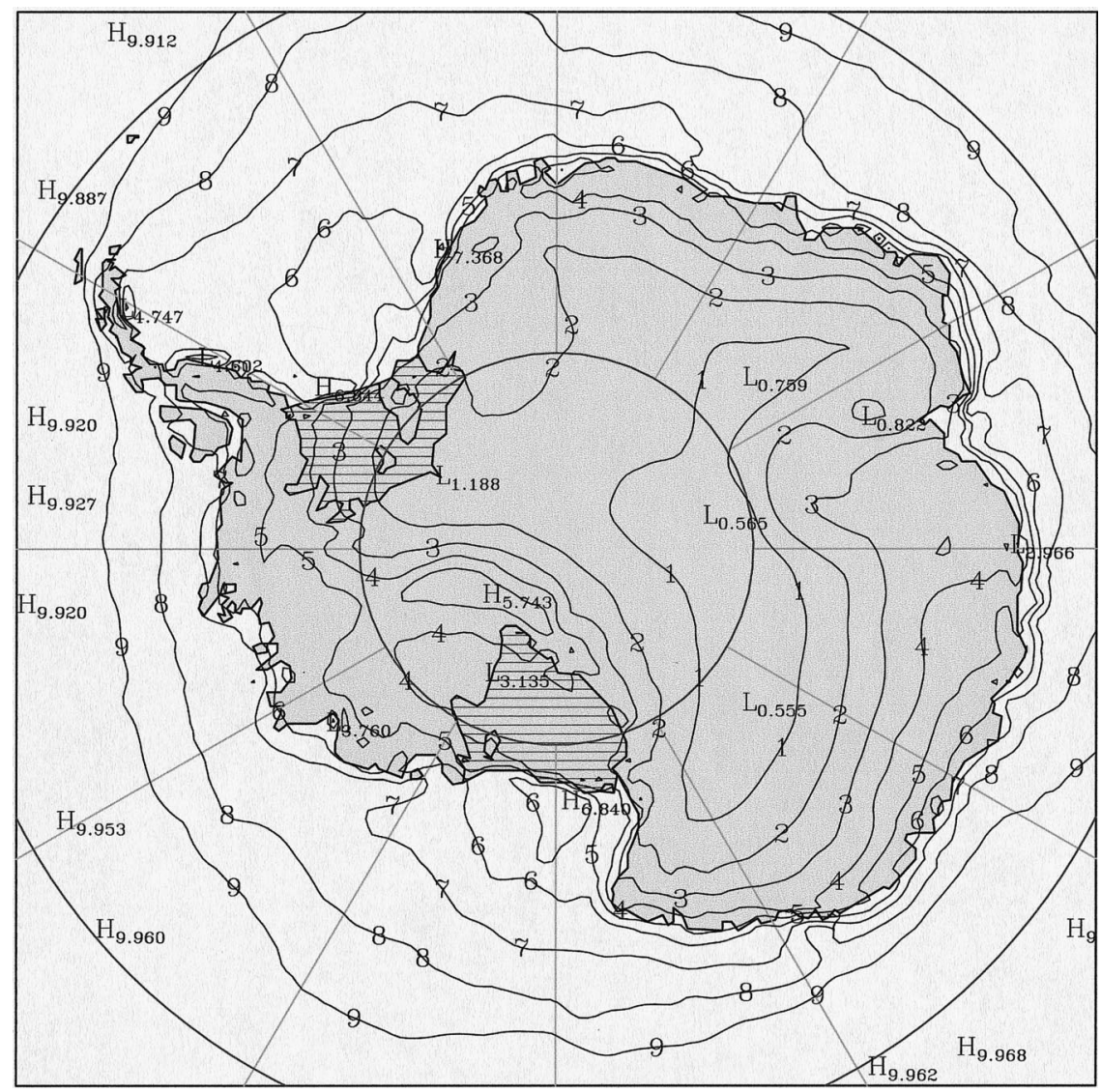

FIG. 10. Mean annual total cloud cover (tenths) in 1993 simulated by Polar MM5.

To give the reader an idea of the spatial performance of PMM5, Table 4 lists the annual (12 month) average bias, rmse, and correlation coefficient for 14 individual sites. In addition, the table gives the average over all 14 sites and over the same 28 sites as in Figs. 14 and 15.

The bias is defined as the difference between the PMM5 monthly mean and the observed monthly mean value of a given variable, and identifies any systematic differences between the PMM5 simulation and the observations. The rmse is calculated as the square root of the monthly averaged squared difference between the observation and the PMM5 simulated value of a given variable at each time, and is a measure of the "typical" absolute difference between the PMM5 and observed values. The correlation coefficient measures the relative agreement between the two datasets. The value at each site and each time represents an independent sample. Thus, there are about 240 samples for calculating averages and statistics for each month and each site. Figures 14 and 15 show that the seasonal cycle in the nearsurface temperature, pressure, wind speed, and wind direction is reproduced by the PMM5 model quite well. The model performance for each near-surface variable is discussed below.

Comparison of the observed and modeled surface pressure and the model verification statistics reveal a positive bias in the modeled surface pressure that persists almost throughout the 12-month period. This bias ranges from -0.1 to $5.0 \mathrm{hPa}$ when averaged over the 28 sites. The persistent biases in the pressure mainly are due to the observation sites near the coast, and no consistent bias in the modeled surface pressure is evident at sites in the interior of Antarctica (Table 4). The spatial distribution of the surface pressure biases suggests that gravity waves generated around the steep coastal slopes and in the stratosphere play an important role in the redistribution of momentum in Antarctica (Yoshiki and Sato 2000). Lifting the top pressure level to increase the gravity wave dissipation during vertical propagation and adjusting the cutoff wavenumber in the upper radiation boundary condition to allow more gravity wave energy to pass through the upper boundary helps reduce the surface pressure biases. One set of sensitivity simulations for July 1993, in which the model top pressure is simply set to $10 \mathrm{hPa}$ without any further modification, does support the above hypothesis. When the top pressure is set to $10 \mathrm{hPa}$ in the sensitivity simulations, the mean sea level pressure biases near the coastal regions derived from the PMM5 simulations and the ECMWF analyses are reduced dramatically in comparison with that calculated from the original simula- 


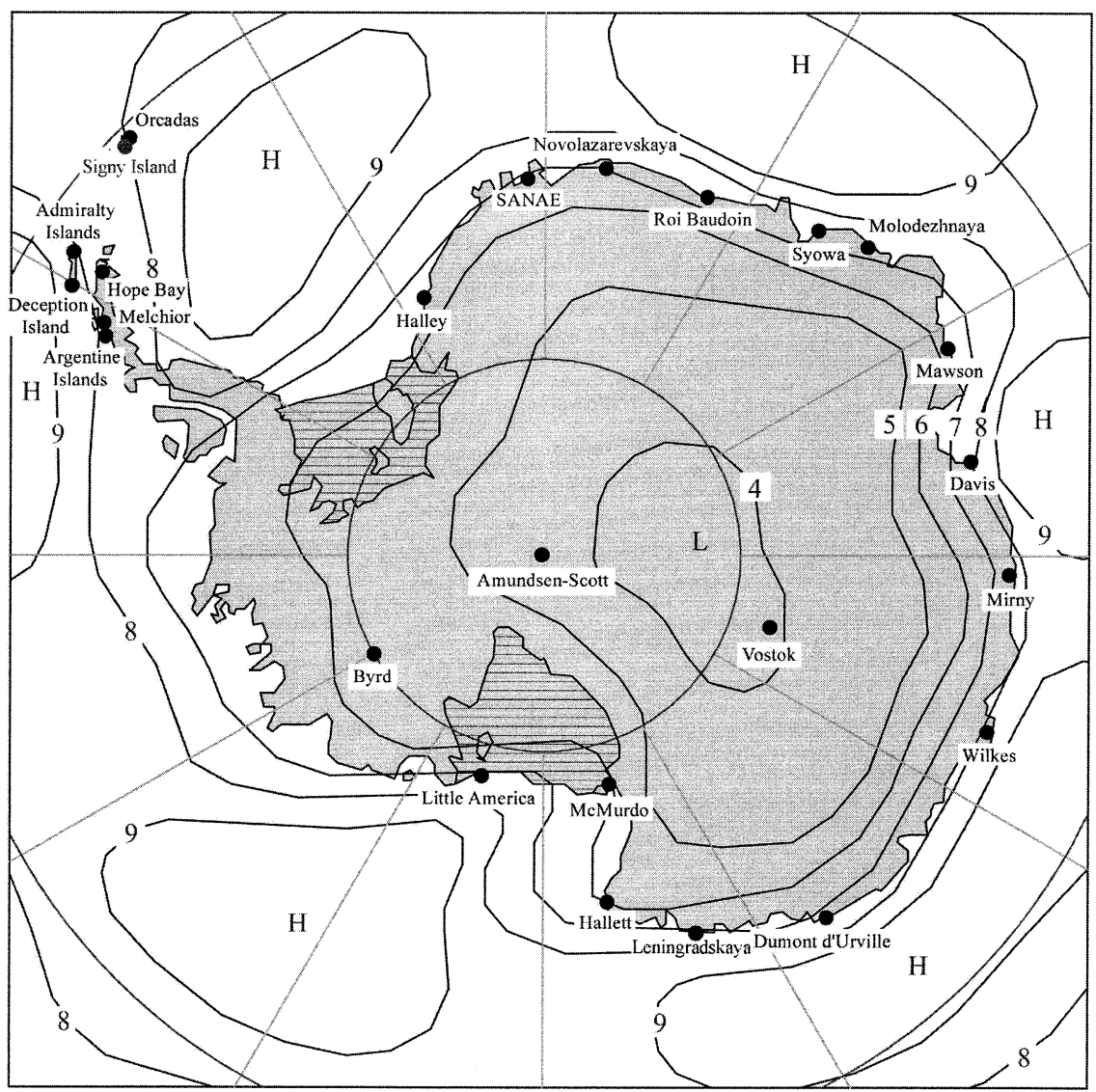

FIG. 11. Mean annual total cloud cover (tenths) from station observations. [After Borisenkov and Dolganov (1982).] Dots show the observation sites used for compilation.

tions (not shown). Figures 16a and 16b show the daily running mean of surface pressure, wind speed, and wind direction generated from the sensitivity simulations (denoted by run 2) and the original simulations (top pressure is $100 \mathrm{hPa}$, denoted by run 1) for average values over 19 coastal sites and 9 interior sites, respectively. It is evident that the persistent biases in the surface pressure mainly are attributable to the observation sites near the coast in the original simulations, and setting the top pressure to $10 \mathrm{hPa}$ reduces the pressure bias by $4.6 \mathrm{hPa}$ when averaged over the 19 coastal sites. Figures $16 \mathrm{a}$ and $16 \mathrm{~b}$ show that setting the top pressure to 10 $\mathrm{hPa}$ does not affect the biases and rmse in wind speed and wind direction significantly at both coastal and interior sites, but makes the pressure bias in the interior worse by $2.1 \mathrm{hPa}(-2.2$ versus $0.1 \mathrm{hPa})$ when averaged over the nine interior sites. Despite the persistent positive biases, the correlations between the observations

TABLE 3. Mean annual and seasonal total cloud cover (tenths) in 1993 calculated from observations and Polar MM5 simulations at eight manned stations (locations given in Fig. 1). Dec, Jan, Feb is DJF; Mar, Apr, May is MAM; Jun, Jul, Aug is JJA; Sep, Oct, Nov is SON; PMM5 = sim; observed = obs; bias = PMM5 - observed.

\begin{tabular}{|c|c|c|c|c|c|c|c|c|c|c|c|c|c|c|c|}
\hline \multirow[b]{2}{*}{ Stations } & \multicolumn{3}{|c|}{ Annual } & \multicolumn{3}{|c|}{ DJF } & \multicolumn{3}{|c|}{ MAM } & \multicolumn{3}{|c|}{ JJA } & \multicolumn{3}{|c|}{ SON } \\
\hline & Sim & Obs & Bias & Sim & Obs & Bias & Sim & Obs & Bias & Sim & Obs & Bias & Sim & Obs & Bias \\
\hline Neumayer & 5.7 & 5.9 & -0.2 & 5.9 & 6.4 & -0.5 & 6.1 & 5.1 & 1.0 & 6.3 & 5.1 & 1.2 & 4.6 & 7.0 & -2.4 \\
\hline South Pole & 2.3 & 4.5 & -2.2 & 1.9 & 6.3 & -4.4 & 2.7 & 3.2 & -0.5 & 2.5 & 2.9 & -0.4 & 1.9 & 5.6 & -3.7 \\
\hline Halley & 4.9 & 6.1 & -1.2 & 3.9 & 5.9 & -2.0 & 5.5 & 6.6 & -1.1 & 5.3 & 4.8 & 0.5 & 4.8 & 6.9 & -2.1 \\
\hline Syowa & 5.1 & 6.5 & -1.4 & 3.1 & 6.8 & -3.7 & 6.4 & 7.1 & -0.7 & 5.5 & 5.4 & 0.1 & 5.4 & 6.9 & -1.5 \\
\hline Mawson & 3.1 & 4.7 & -1.6 & 2.7 & 5.2 & -2.5 & 3.9 & 4.3 & -0.4 & 3.9 & 4.7 & -0.8 & 1.9 & 4.6 & -2.7 \\
\hline Davis & 3.9 & 5.9 & -2.0 & 3.0 & 6.0 & -3.0 & 4.5 & 6.3 & -1.8 & 4.6 & 5.1 & -0.5 & 3.5 & 6.3 & -2.8 \\
\hline Vostok & 0.6 & 2.0 & -1.4 & 0.8 & 1.7 & -0.9 & 0.4 & 1.5 & -1.1 & 0.7 & 1.6 & -0.9 & 0.7 & 3.3 & -2.6 \\
\hline Casey & 6.3 & 7.1 & -0.8 & 4.9 & 7.8 & -2.9 & 6.8 & 7.5 & -0.7 & 8.0 & 6.7 & 1.3 & 5.5 & 6.3 & -0.8 \\
\hline Avg. Bias & & & -1.3 & & & -2.5 & & & -0.7 & & & 0.1 & & & -2.3 \\
\hline
\end{tabular}




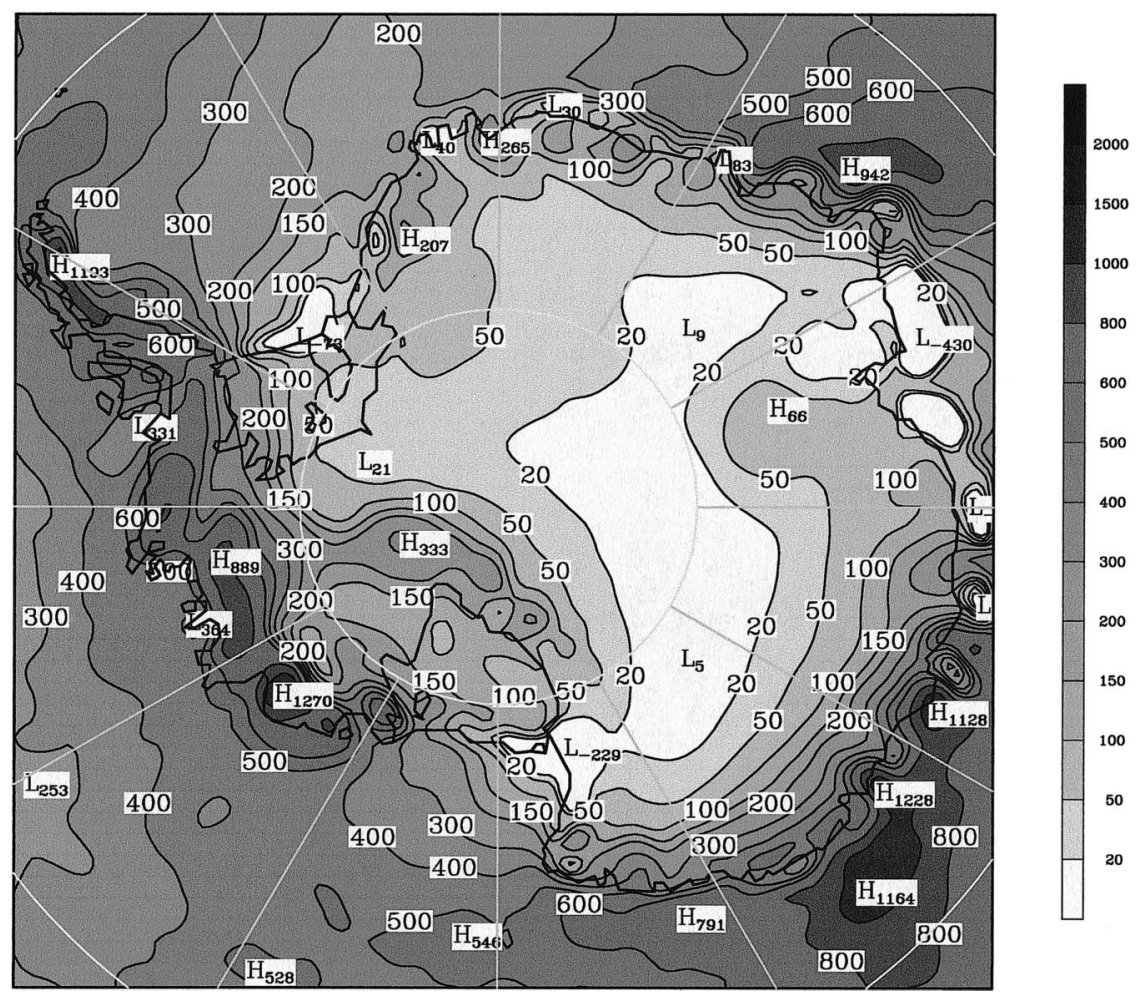

FIG. 12. Annual precipitation minus sublimation (units, $\mathrm{mm} \mathrm{yr}^{-1}$ ) in 1993 simulated by Polar MM5.

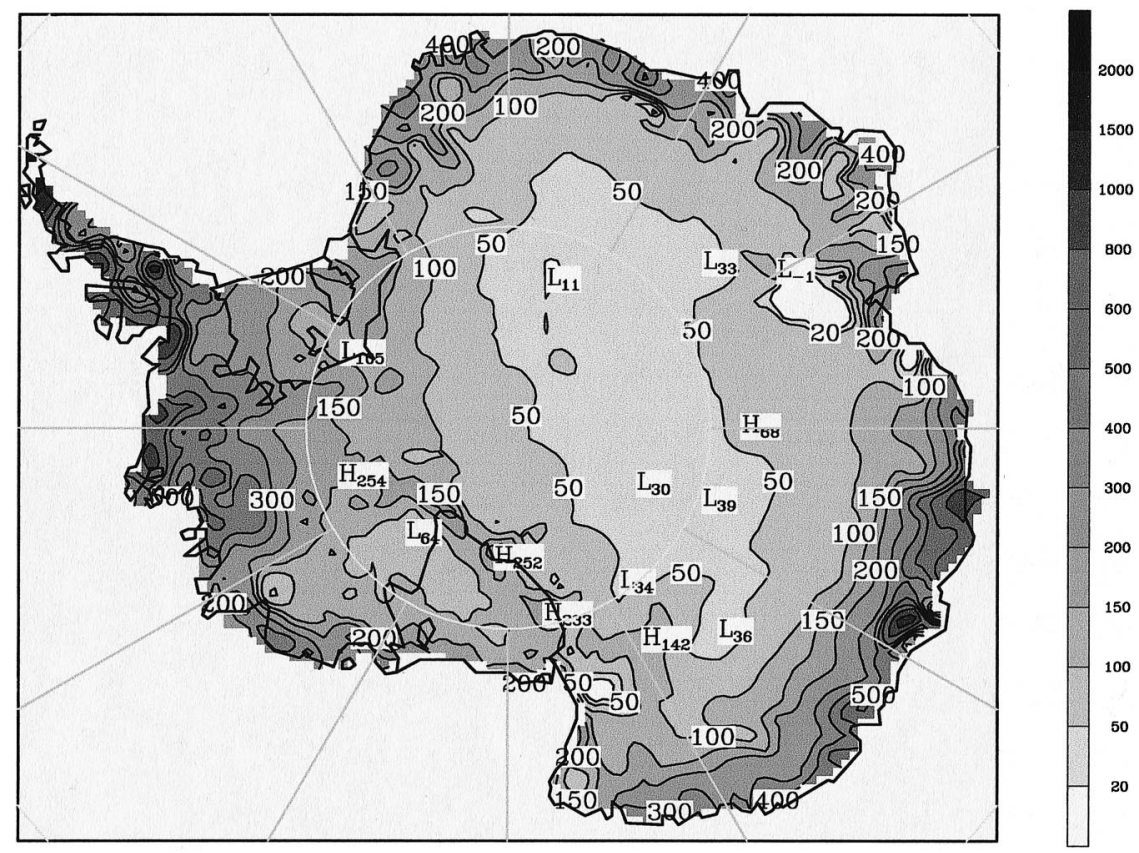

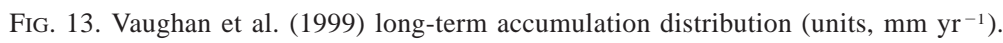




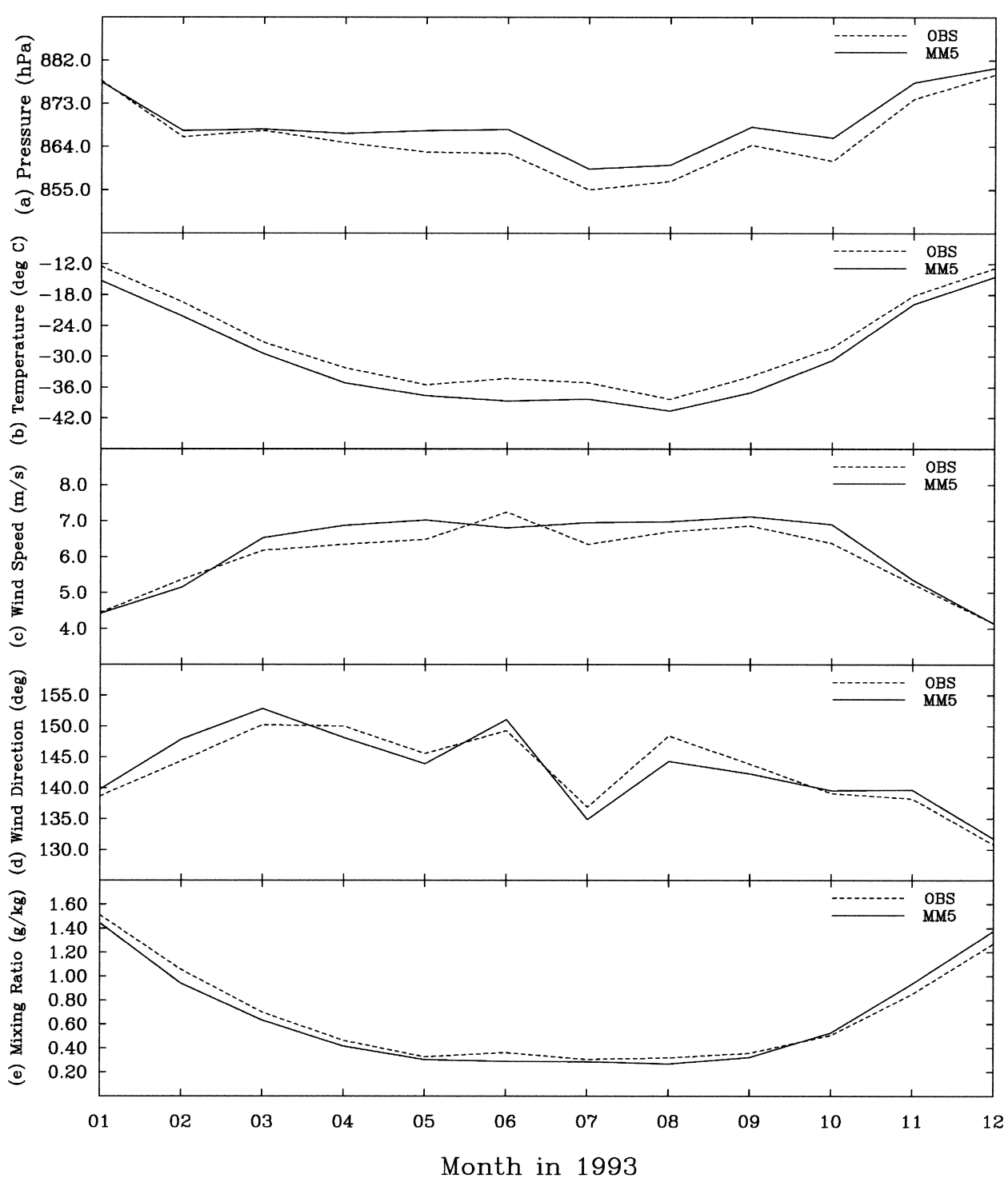

FIG. 14. Monthly mean values calculated from the Polar MM5 simulations (solid lines) and from the AWS and manned stations (dashed lines). The monthly mean values have been averaged over 28 sites (and model grid points) as described in the text.

and the model simulations for the surface pressure are high $(0.70-0.88)$ when averaged over the 28 sites and are indicative of the high level of skill present in the PMM5 simulations. The rmse ranges from 4.1 to 8.0 $\mathrm{hPa}$ and increases gradually from the summer to the winter months, as the observed pressure variability increases.

Similar to the surface pressure, the near-surface air temperature is well simulated by PMM5. The monthly mean bias averaged over the 28 sites ranges from $-4.2^{\circ}$ to $-1.1^{\circ} \mathrm{C}$. The annual average statistics in Table 4 indicate that the interior sites make the most significant contribution to this cold bias. The larger negative biases in the winter are mainly caused by the low downward longwave radiation under clear skies in the interior of the Antarctic plateau for the CCM2 radiation scheme. The correlation between the observed and modeled nearsurface temperature is not as large as that for the surface pressure when averaged over the 28 sites. The rmse averaged over the 28 sites varies from $3.8^{\circ}$ to $7.9^{\circ} \mathrm{C}$. It is at a minimum during the summer months, when synoptic forcing is weakest and the diurnal variability is dominant, and is at a maximum during the more synoptically active winter months.

The seasonal cycles of modeled wind speed and wind direction are very similar to the observations when averaged over the 28 sites. The model verification statistics reveal an agreement between the simulations and the observations (correlations around 0.65 ) and a small bias between the observed and modeled wind direction. 


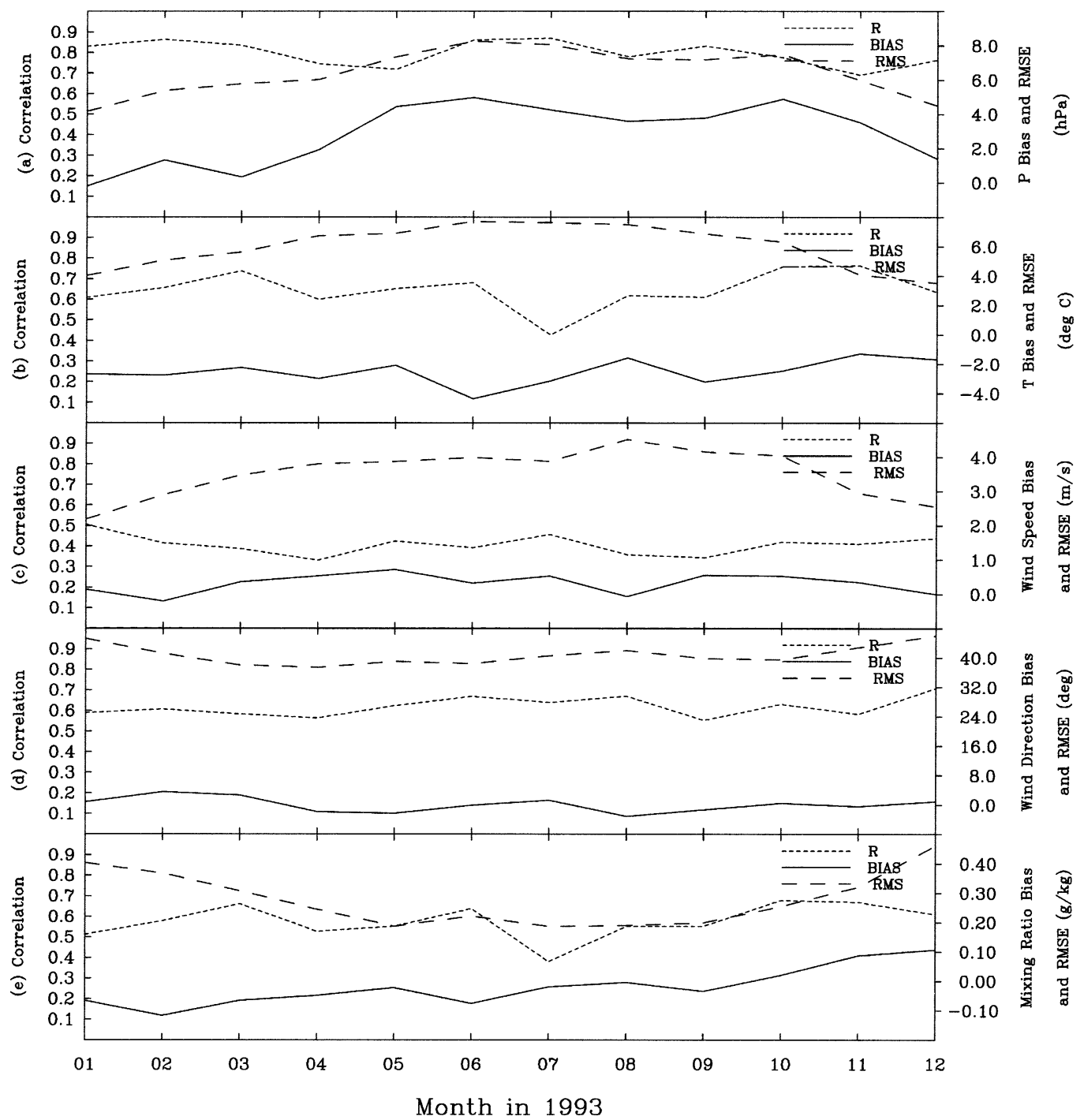

FIG. 15. Monthly model verification statistics averaged over 28 sites.

Among five variables shown in Fig. 15 the correlation between the observed and modeled wind speed is the lowest, with little seasonal variation. It is believed that the errors in the ECMWF initialization, coarse spatial resolution (smoothing of topography), and cold biases in near-surface temperature, which have important effects on the predicted katabatic flow, are the main causes of the biases in wind speed. Although the correlation of wind speed is low for the 3-h timescale, there is good agreement between the monthly mean values of observed and modeled wind speed, and the model skillfully captures the trends.

The model also reproduces seasonal variations of the mixing ratio accurately, although it has a persistent dry bias (ranges from -0.13 to $0.11 \mathrm{~g} \mathrm{~kg}^{-1}$ ) except in November and December 1993 (Figs. 14 and 15). The correlation between the modeled and observed water vapor mixing ratio is qualitatively similar to that for the tem- perature but is slightly lower for the mixing ratio than the temperature. The correlation for the mixing ratio, averaged over the 28 sites, ranges from 0.40 to 0.70 and has similar values at the individual sites where data are available. The similarity between the model correlation for the water vapor mixing ratio and air temperature is caused by the strong dependence of the water vapor content of the atmosphere on the air temperature.

\section{c. Synoptic variability}

The synoptic variability in the model simulations is evaluated by comparing monthly time series of the twice-daily upper-air rawinsonde data and 3-hourly near-surface AWS and manned station observations with that of the corresponding PMM5 output. The monthly time series of air temperature, dewpoint temperature, and geopotential height at the $500-\mathrm{hPa}$ pressure level 


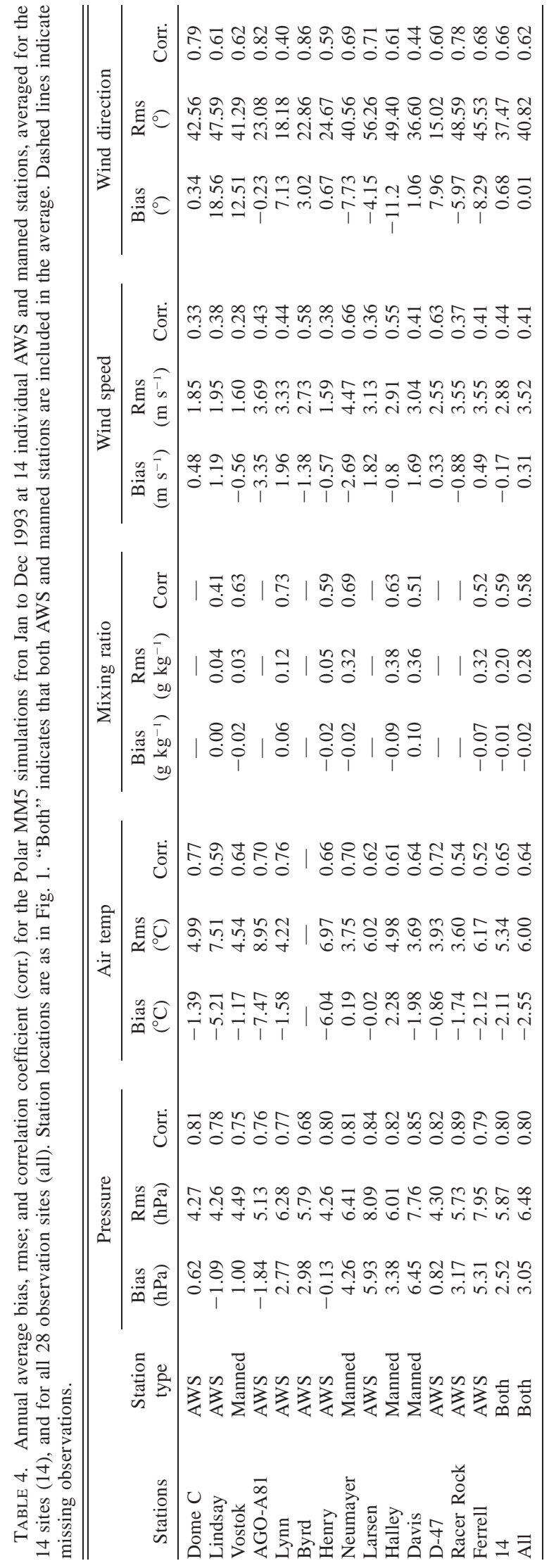

averaged over five sites (South Pole, Mawson, Syowa, Casey, and Halley), and near-surface 3-hourly wind speed, wind direction, and mixing ratio for the Dome $\mathrm{C}$ and Neumayer sites for January and July 1993 are presented in Figs. 17 and 18-21 respectively. The time series for January-March 1993 at Dome C is also plotted using a daily (eight point) running mean in order to eliminate the diurnal cycle (Fig. 22). Dome $\mathrm{C}$ and Neumayer were selected for this analysis because they are representative of the model skill at the other AWS and manned sites, and provide an evaluation of the model over a range of environments on the Antarctic ice sheet (Neumayer, coastal site with low elevation; Dome C, central site with high elevation). The months of January and July have been selected for further analysis to provide a contrast between the two extreme months of the annual cycle. Also, the model skill (as determined by the correlation coefficients shown in Fig. 15) during January and July 1993 is similar to that for most other months during the 12-month period of the model simulations.

The PMM5 simulations accurately capture the synoptic variability at the $500-\mathrm{hPa}$ pressure level in the observed temperature, dewpoint temperature, and geopotential height during both months (Fig. 17). At 500 $\mathrm{hPa}$, the differences between the observations and simulations are generally less than $2^{\circ} \mathrm{C}$ for both the temperature and dewpoint temperature, and $20 \mathrm{~m}$ for the geopotential height when averaged over the five sites. Also, trends in the time series of all three variables are well reproduced by the PMM5. The model has similarly good performance at other upper-air levels except above the 200-hPa pressure level over the entire domain and below the $600-\mathrm{hPa}$ pressure level over the interior of Antarctica. Above the 200-hPa pressure level the model performance is strongly influenced by the upper boundary condition, and the model air temperature is generally warmer (about $7^{\circ} \mathrm{C}$ in the annual mean) than the observations when averaged over the same five sites. The sensitivity simulations mentioned above also resolve the vertical temperature structure better and reduce the associated warm bias above the 200-hPa pressure level. At the interior sites of Antarctica a significant low-level dry bias (in absolute terms) is found in the PMM5 simulations, especially during the winter. It is believed that this bias is mainly caused by the inadequate representation of the low-level temperature inversion in the ECMWF analyses, which causes the model initial temperatures to be too cold and thus the model initial mixing ratios to be too low.

For the surface pressure, one interesting feature can be found in the way the model tracks the observations and how it responds to reinitialization every other day (Figs. 18-22). In correspondence to the model reinitialization every other day clear jumps can be found at both sites at 2-day intervals. These jumps represent a mixture of the biases in the simulation of surface pressure introduced from the model reinitialization and a 


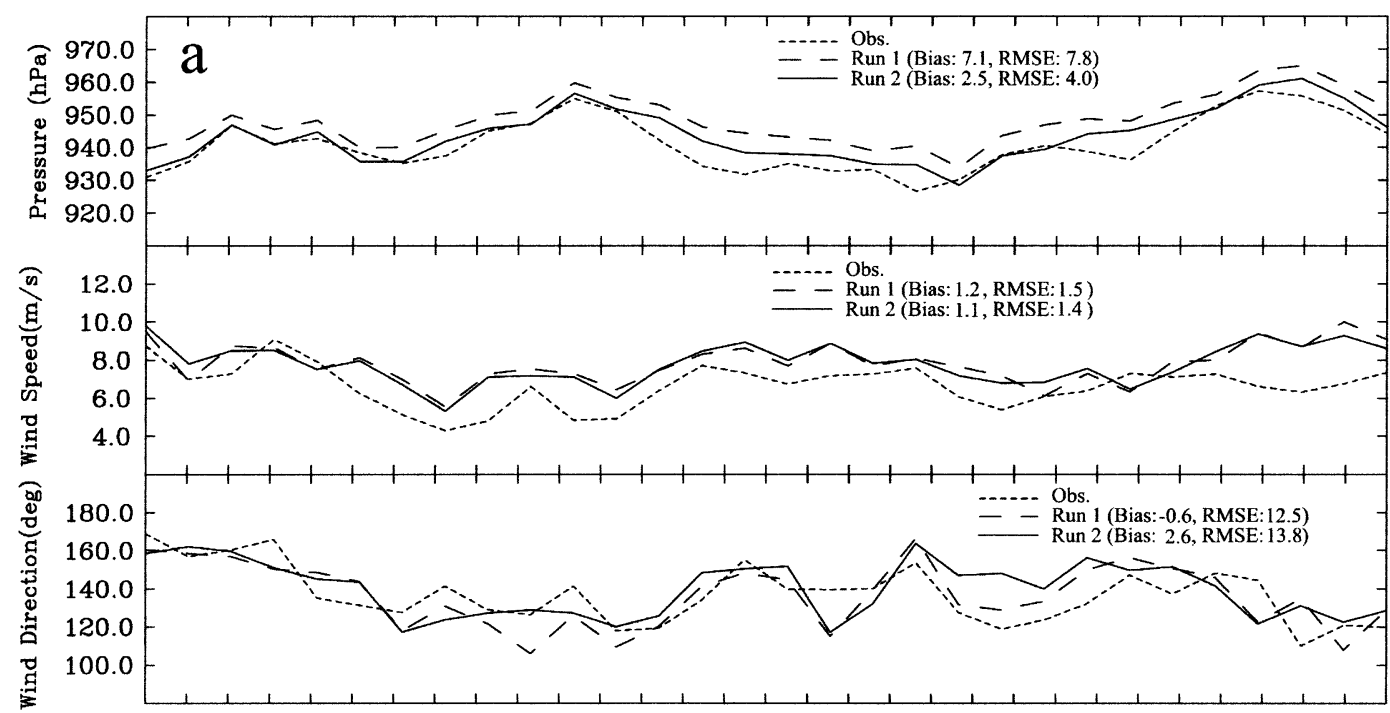

010203040506070809101112131415161718192021222324252627282930

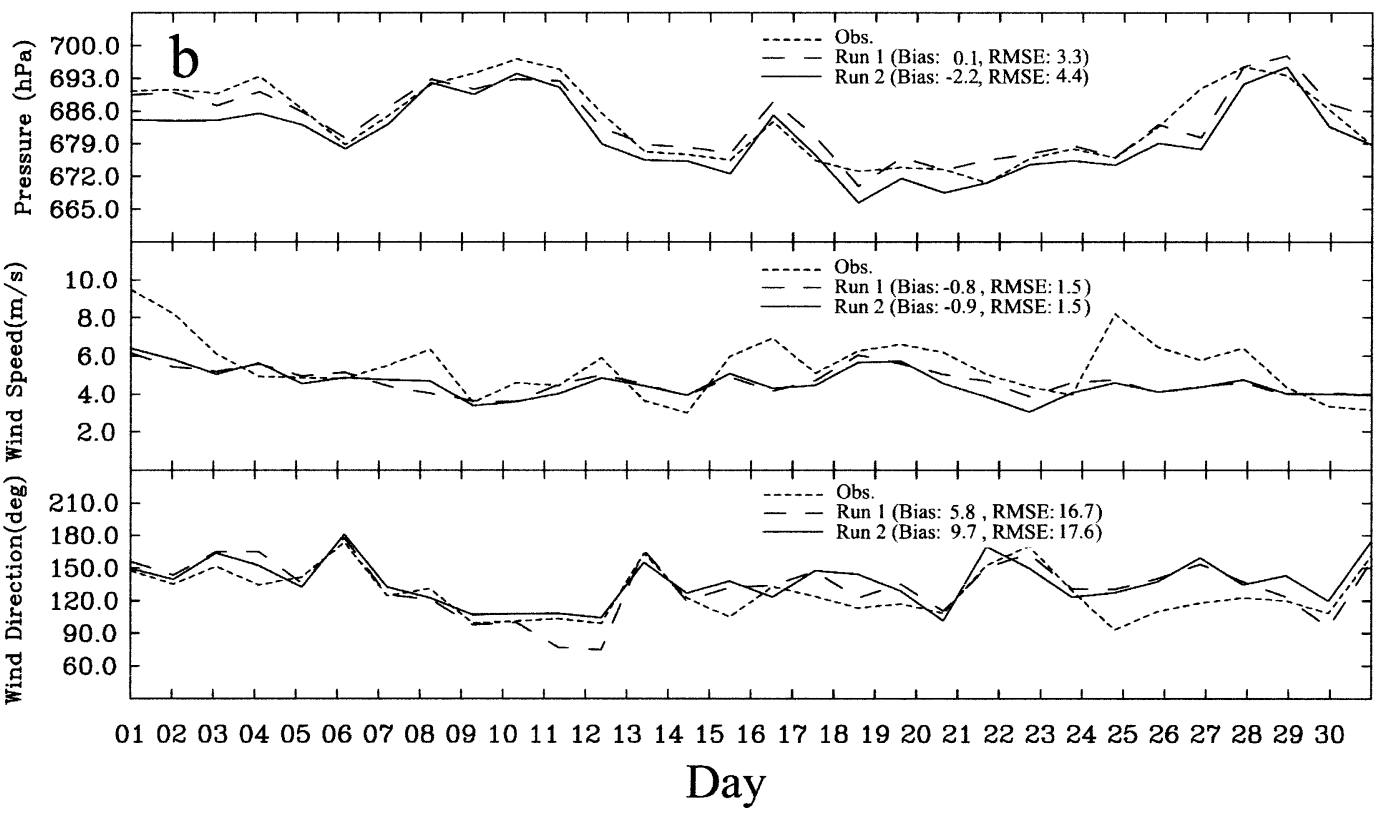

FIG. 16. Daily running mean calculated from the Polar MM5 original simulations (denoted by run 1 in dashed lines), sensitivity simulations (denoted by run 2 in solid lines), and station observations (dotted lines) for Jul 1993. The daily running mean values have been averaged over (a) 19 coastal sites and (b) 9 interior sites, respectively. Runs 1 and 2 represent simulations with the model top pressure set to 100 and $10 \mathrm{hPa}$, respectively.

partial failure of PMM5 to simulate the natural synoptic variability at both sites. At Dome C in January, it appears that the PMM5 simulations are being pulled back to the observations every 2 days (Fig. 18). This might reflect a failure of PMM5 to accurately reproduce the cloud cover and its interaction with radiation during the 24-h daylight in the interior of the Antarctic. In contrast the PMM5 simulations are pulled away from the observations at Dome C in July (Fig. 20) by the reini- tialization every 2 days. It seems that the PMM5 has good performance in reproducing the synoptic variability in the interior of the Antarctic during the 24-h darkness, and biases present in the initialization fields (resulting from the surface inversion during the initialization procedure) superimpose additional errors in the simulations of surface pressure. At Neumayer the jumps between the short simulations are less apparent in the pressure simulations than at Dome $\mathrm{C}$, and most of the 


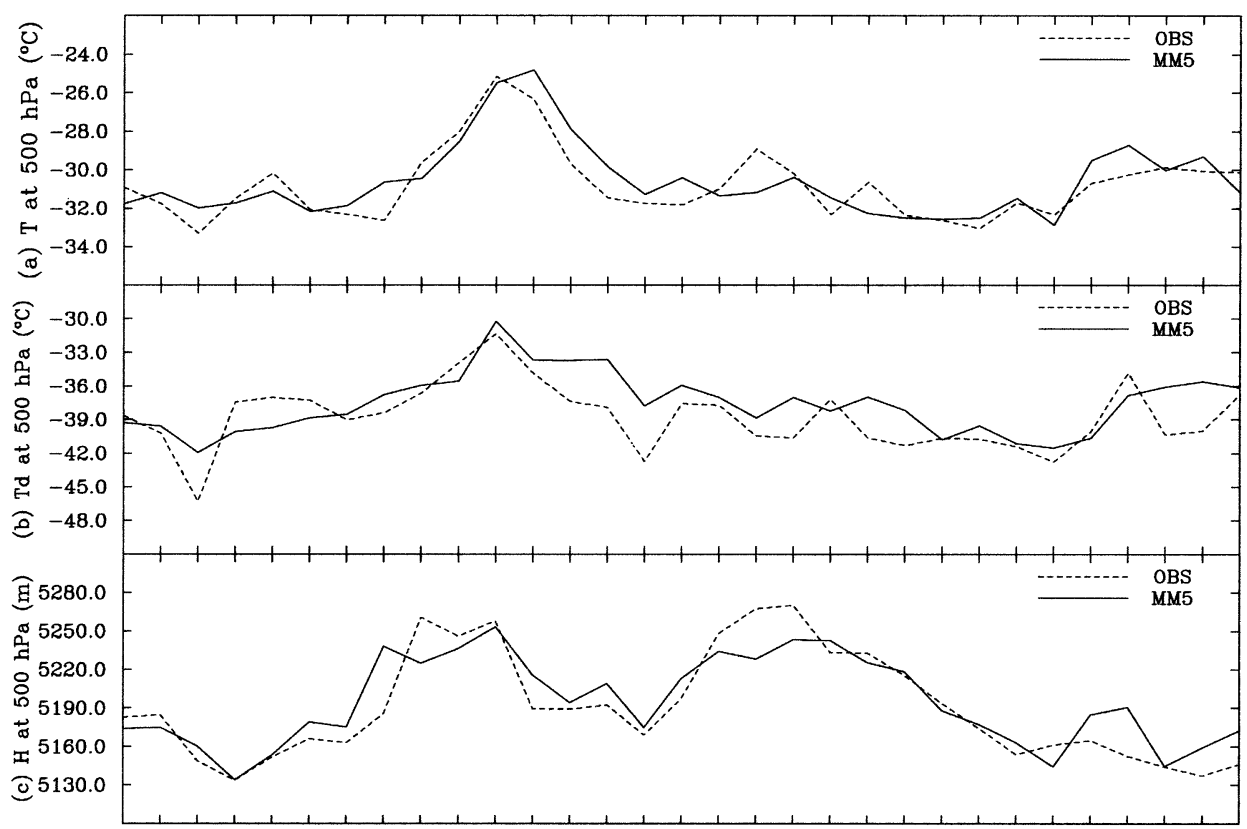

$\begin{array}{lllllllllllllllllllllllllllllll}01 & 02 & 03 & 04 & 05 & 06 & 07 & 08 & 09 & 10 & 11 & 12 & 13 & 14 & 15 & 16 & 17 & 18 & 19 & 20 & 21 & 22 & 23 & 24 & 25 & 26 & 27 & 28 & 29 & 30 & 31\end{array}$

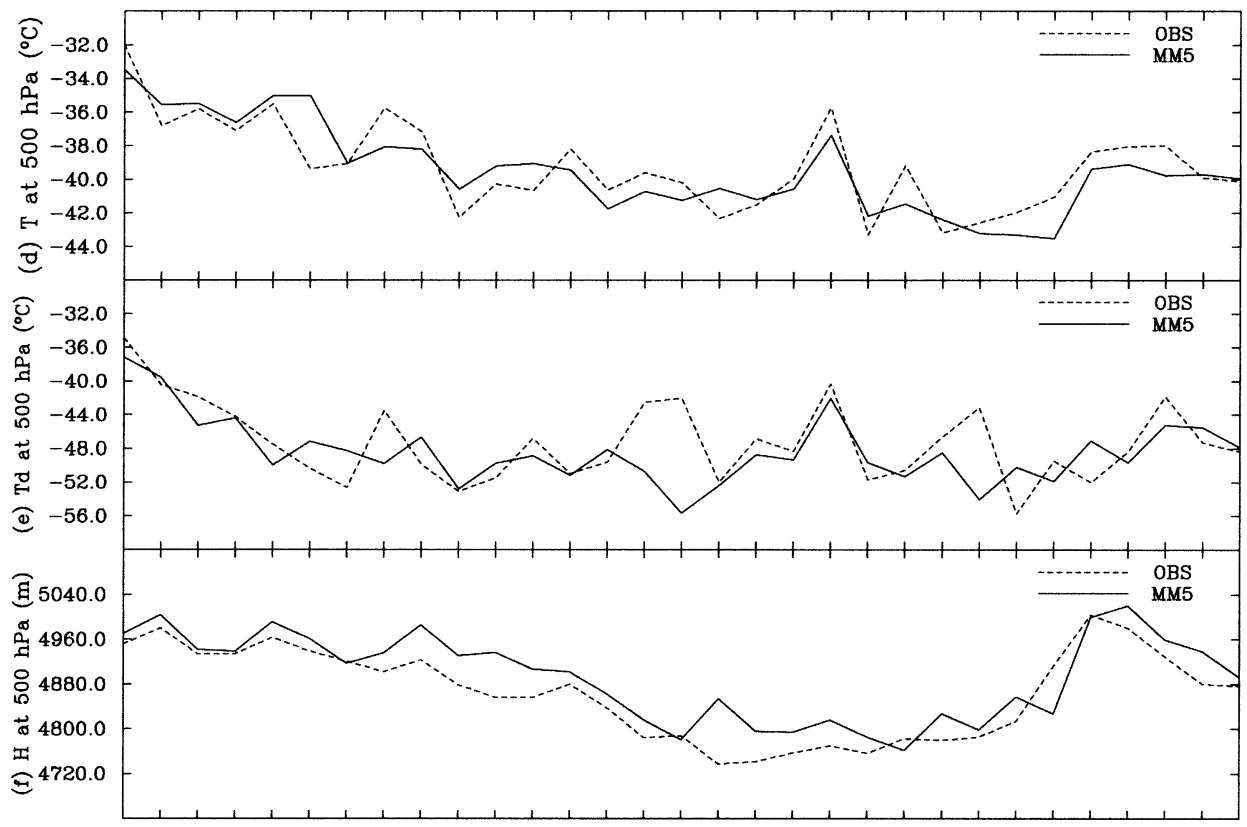

$\begin{array}{lllllllllllllllllllllllllllllll}01 & 02 & 03 & 04 & 05 & 06 & 07 & 08 & 09 & 10 & 11 & 12 & 13 & 14 & 15 & 16 & 17 & 18 & 19 & 20 & 21 & 22 & 23 & 24 & 25 & 26 & 27 & 28 & 29 & 30 & 31\end{array}$

Day

FIG. 17. Time series of variables at $500 \mathrm{hPa}$ calculated from the Polar MM5 simulations (solid lines) and station observations (dotted lines) for (a)-(c) Jan and (d)-(f) Jul 1993. The variables have been averaged over five sites.

variability is well represented by the PMM5 (Figs. 19 and 21). There is little diurnal modification of the pressure at these sites, during January and July. The timing of some of the pressure extremes in the model time series differs slightly from the observations, although no consistent phase lag is apparent. Overall, there is good agreement between the modeled and observed pressure time series.

During January 1993 the diurnal cycle of the temperature dominates the temperature variability in the observations and the model simulations (Figs. 18 and 19), and is discussed below. Considering the daily run- 

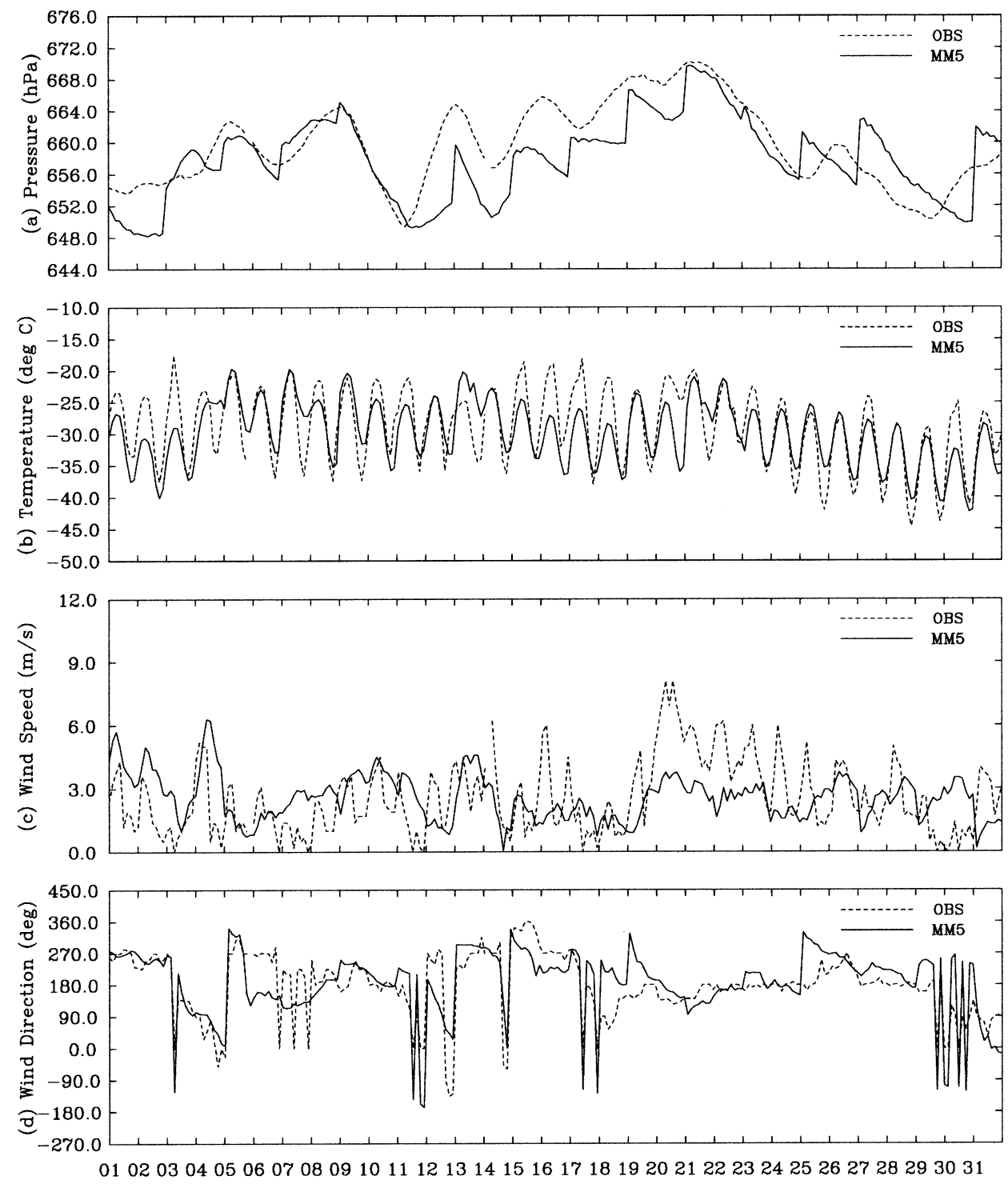

Day

FIG. 18. Monthly time series of 3-hourly station observations (dotted lines) and Polar MM5 simulations (solid lines) at Dome C for Jan 1993.

ning mean of the air temperature, there is little synopticscale variability in the observed temperature at Dome $\mathrm{C}$ in the summer time (Fig. 22). During July 1993, the synoptic variability dominates the variability in the monthly temperature time series at both sites (Figs. 20b and $21 \mathrm{~b}$ ). While a few obvious large discrepancies between the simulations and observations can be found in Figs. 18-21, most of the synoptic variability in the daily temperatures is well represented by the PMM5 simulations.

The PMM5 simulations capture much of the synoptic variability in the observed wind speed during both months (Figs. 18-21). At both sites, during January and July 1993, the model represents the multiday trends of increasing or decreasing wind speed as observed by the AWS and manned stations (panel c of Figs. 18-21). In addition, the monthly averages of wind speed are accurately represented by the model, although there are some differences in the details of the observed and modeled time series. However, the model underestimates the wind speed variance such that periods of higher wind speeds are not well simulated. This might arise from the model cold biases, and associated potential damping of the turbulent mixing of higher momentum air from the elevated katabatic jet to the surface when the colder surface temperature increases the near-surface stability.

The magnitude and variability of wind direction at both Dome $\mathrm{C}$ and Neumayer are accurately depicted by 


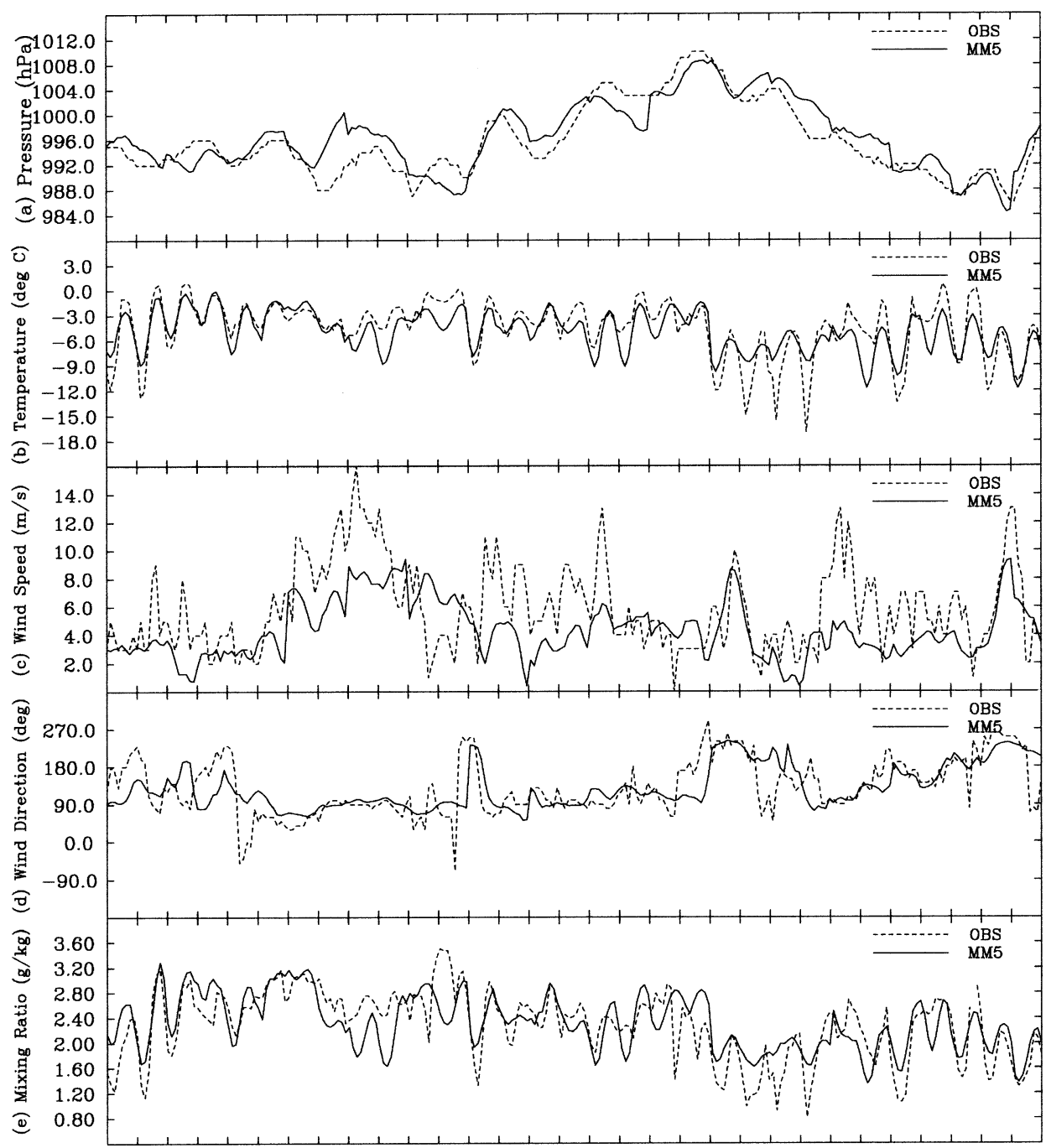

01020304050607080910111213141516171819202122232425262728293031

Day

FIG. 19. Monthly time series of 3-hourly station observations (dotted lines) and Polar MM5 simulations (solid lines) at Neumayer for Jan 1993.

the model during both January and July (Figs. 18d21d). This is consistent with the high correlation of the modeled and observed wind direction for the annual mean shown in Table 4. At Dome C, the annual average bias is as low as $0.34^{\circ}$, and correlation between the observation and the simulation is as high as 0.79 .

During January, the modeled and observed mixing ratio exhibits a pronounced diurnal cycle superimposed on the synoptic variations (Fig. 19e). On the synoptic timescale, many of the significant variations in the mixing ratio are depicted by the model simulations. Some of the errors in the modeled mixing ratio time series mirror the errors in the modeled temperature time series, indicating the importance of accurate temperature simulations for accurate representation of the atmospheric water vapor. The model captures the timing of most of the maxima and synoptic variability in the observed mixing ratio time series for both summer and winter at Neumayer (Figs. 19e and 21e).

\section{d. Diurnal cycle}

The average diurnal cycle for selected variables is calculated for each month as the monthly averaged departure from the daily mean at each observation time for each dataset (3-hourly AWS and manned station observations or MM5 output) separately. The average diurnal cycle of temperature, water vapor mixing ratio, wind speed, and zonal and meridional wind components at Mawson and Sandra for January 1993 are shown in 

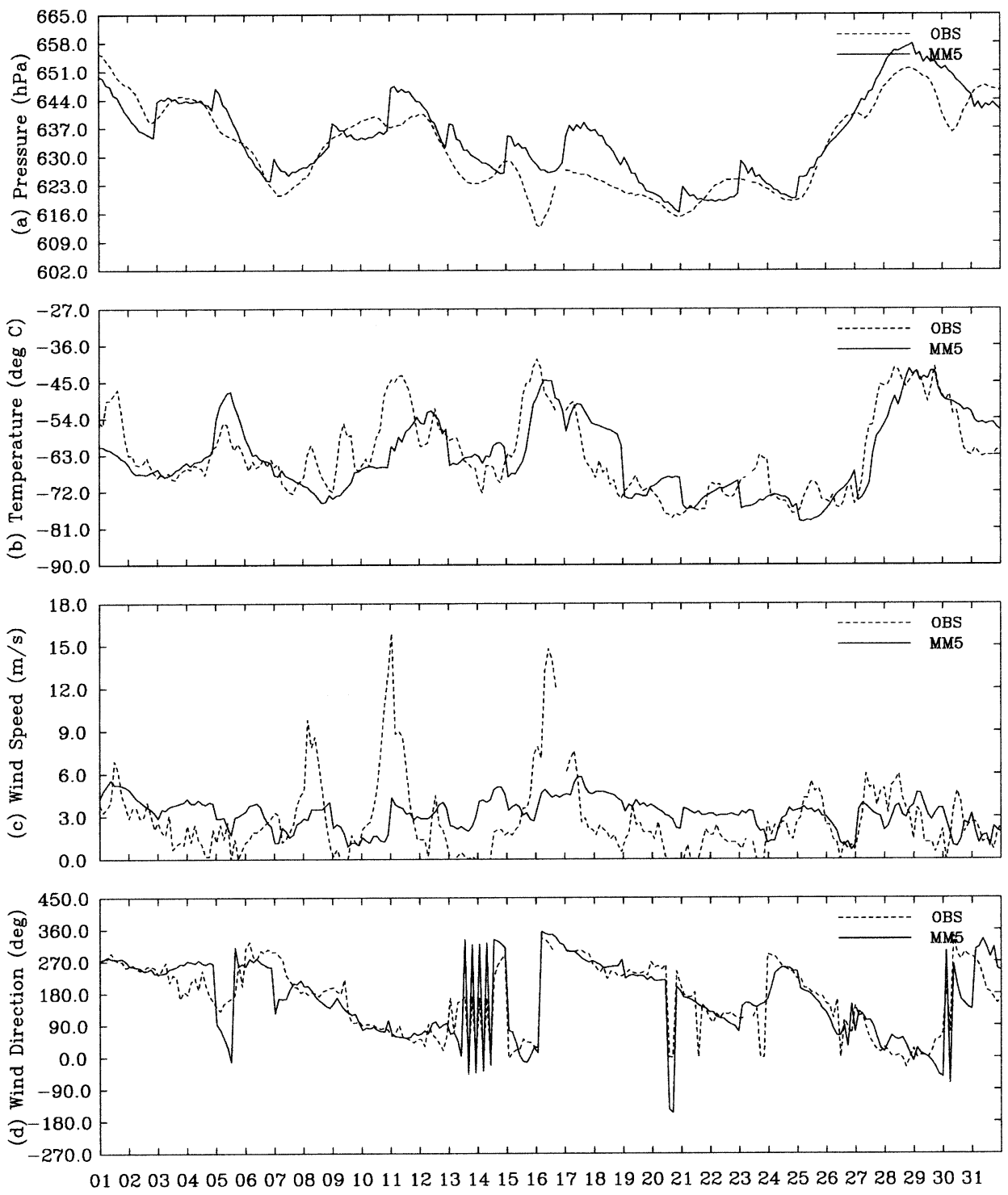

Day

FIG. 20. Monthly time series of 3-hourly station observations (dotted lines) and Polar MM5 simulations (solid lines) at Dome C for Jul 1993.

Figs. 23 and 24. The model captures the timing of the maxima and minima in the diurnal cycle of observed temperature, mixing ratio, and wind speed.

At Mawson, the observations reveal a smaller diurnal temperature range than is simulated by the PMM5 (Fig. 23). This difference is due primarily to the coarse spatial resolution of the model $(60 \mathrm{~km})$, in which the marinecontinental transition cannot be well captured. At Sandra, the magnitude of the mean diurnal cycle of air temperature is very similar between observations and PMM5 simulations (Fig. 24). The simulations lead the observations slightly $(<3 \mathrm{~h})$. This difference might be related to the model capability to represent the evolution of the boundary layer over the ice sheet as discussed below.

The PMM5 simulated average diurnal cycle of the water vapor mixing ratio also closely matches the observed diurnal cycle. Differences between the modeled and observed diurnal cycle of the water vapor mixing ratio are qualitatively similar to the errors in the modeled diurnal temperature cycle. As discussed above, accurate simulations of the low-level moisture content of the atmosphere require accurate simulations of the near-surface air temperature.

A pronounced diurnal cycle in the near-surface wind speed, with a maximum during the period of minimum 


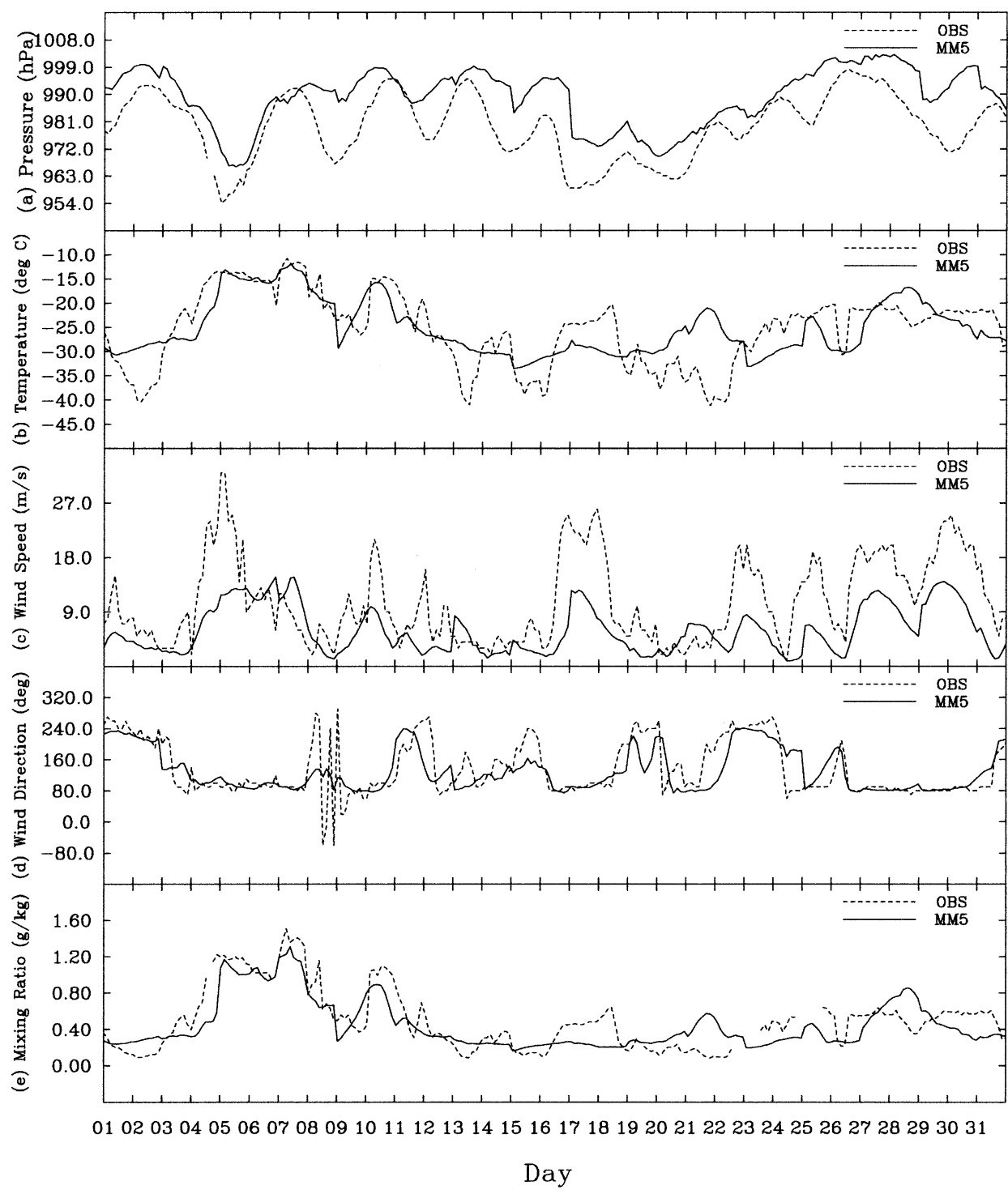

FIG. 21. Monthly time series of 3-hourly station observations (dotted lines) and Polar MM5 simulations (solid lines) at Neumayer for Jul 1993.

air temperature, is evident in the PMM5 simulations (Figs. 23 and 24). This behavior is consistent with primarily katabatically forced winds. The AWS observations at Mawson and Sandra also indicate a pronounced diurnal cycle in the observed wind speeds. Both the observations and PMM5 simulations show a 3-6-h lag of the maximum wind speed relative to the minimum air temperature. Other observations of the diurnal cycle of katabatic winds in Greenland and Antarctica indicate a similar lag in the maximum wind speed relative to the minimum air temperature (Wendler et al. 1988; van den Broeke 1996; Heinemann 1999). This lag has been attributed to a "time lag required for the gravity driven wind to react to changes in the inversion strength" (Wendler et al. 1988) and to "the inertial response of the wind field to the thermal forcing" (van den Broeke 1996). An alternate explanation may involve the turbulent mixing of highermomentum air from the elevated katabatic jet to the surface as the near-surface stability begins to decrease (as the air temperature increases). This mixing becomes increasingly important as the daytime heating progresses, but the diurnal decay of the katabatic jet causes the maximum wind speed at the surface to occur at a time intermediate between the coldest temperature and strongest katabatic flow aloft, and the warmer daytime temperatures and enhanced turbulent coupling of the surface winds to the elevated katabatic jet. This process would require a very accurate, and high-resolution, representation of the boundary layer over the ice sheet for accurate depiction of the diurnal cycle of the wind speed in a numerical model. 

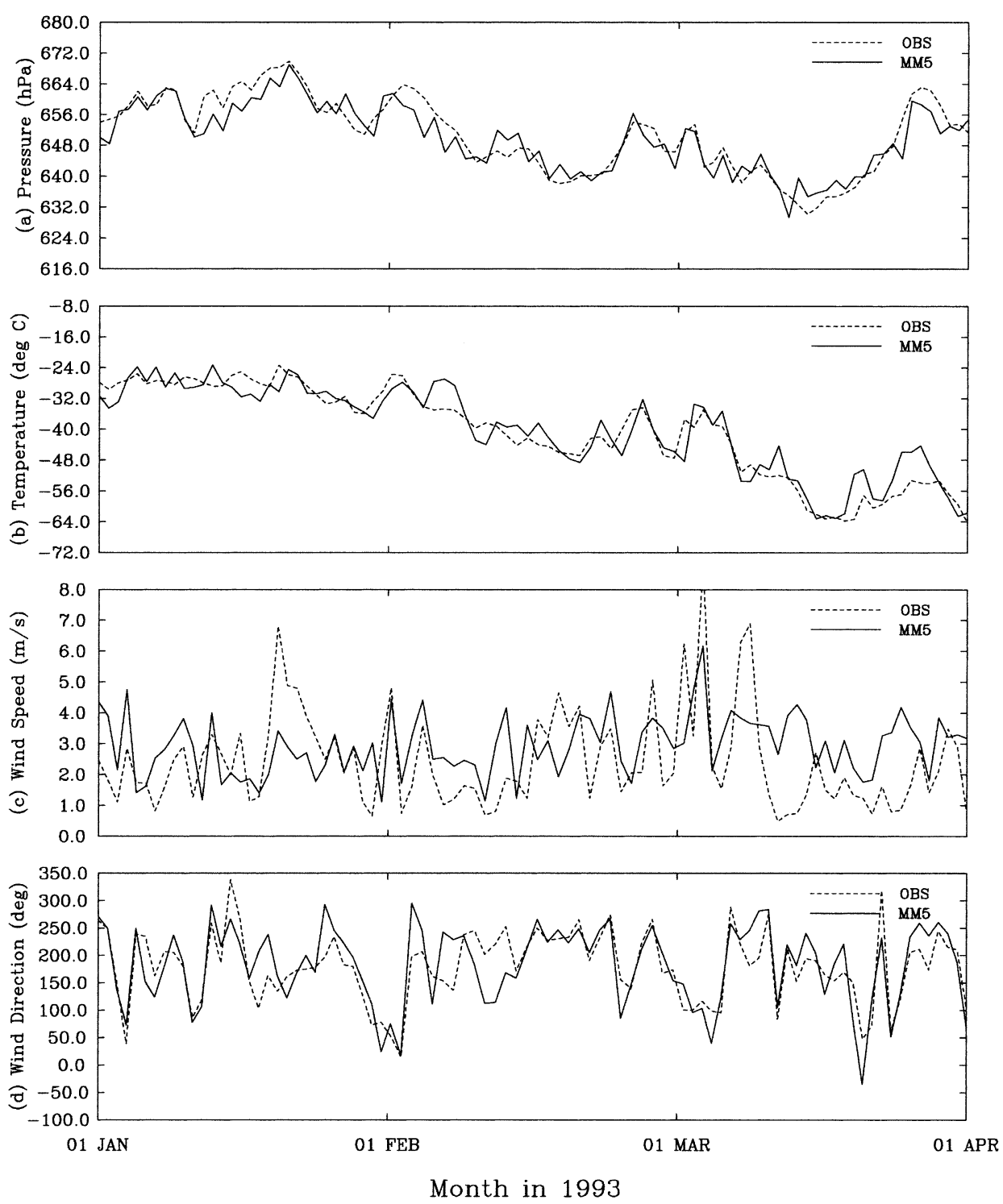

FIG. 22. Daily running mean calculated from the Polar MM5 simulations (solid lines) and station observations (dotted lines) at Dome C for Jan-Mar 1993.

\section{Summary}

Evaluation of a complete annual cycle of 72-h nonhydrostatic mesoscale model simulations of the Antarctic atmospheric circulation using the Polar MM5 is presented. The performance of the Polar MM5 has been evaluated over Antarctica for timescales from annual to diurnal. A comparison of a year-long series of shortterm simulations of the atmospheric state with observations from AWS and manned stations and climatological maps shows that simulations from Polar MM5 capture both the large- and regional-scale circulation features with generally small bias in the modeled variables. On the annual timescale the largest errors in the model simulations are the colder near-surface temperature, deficient total cloud cover, and deficient precip- itation minus sublimation over the interior of the Antarctic plateau. On the seasonal timescale a persistent positive surface pressure bias near the coast, near-surface cold bias and low-level dry bias in the interior of Antarctica, and warm bias at upper model levels are found in the model simulations. The observed synoptic variability of the pressure, temperature, wind speed, wind direction, and water vapor mixing ratio, as well as the diurnal cycle of temperature, wind speed, and water vapor mixing ratio, are reproduced by the Polar MM5 with reasonable accuracy. Over all timescales the Polar MM5 is most skillful in the prediction of the surface pressure, temperature, wind direction, and water vapor mixing ratio, with less skillful predictions of wind speed and many of the strong wind events being missed. 


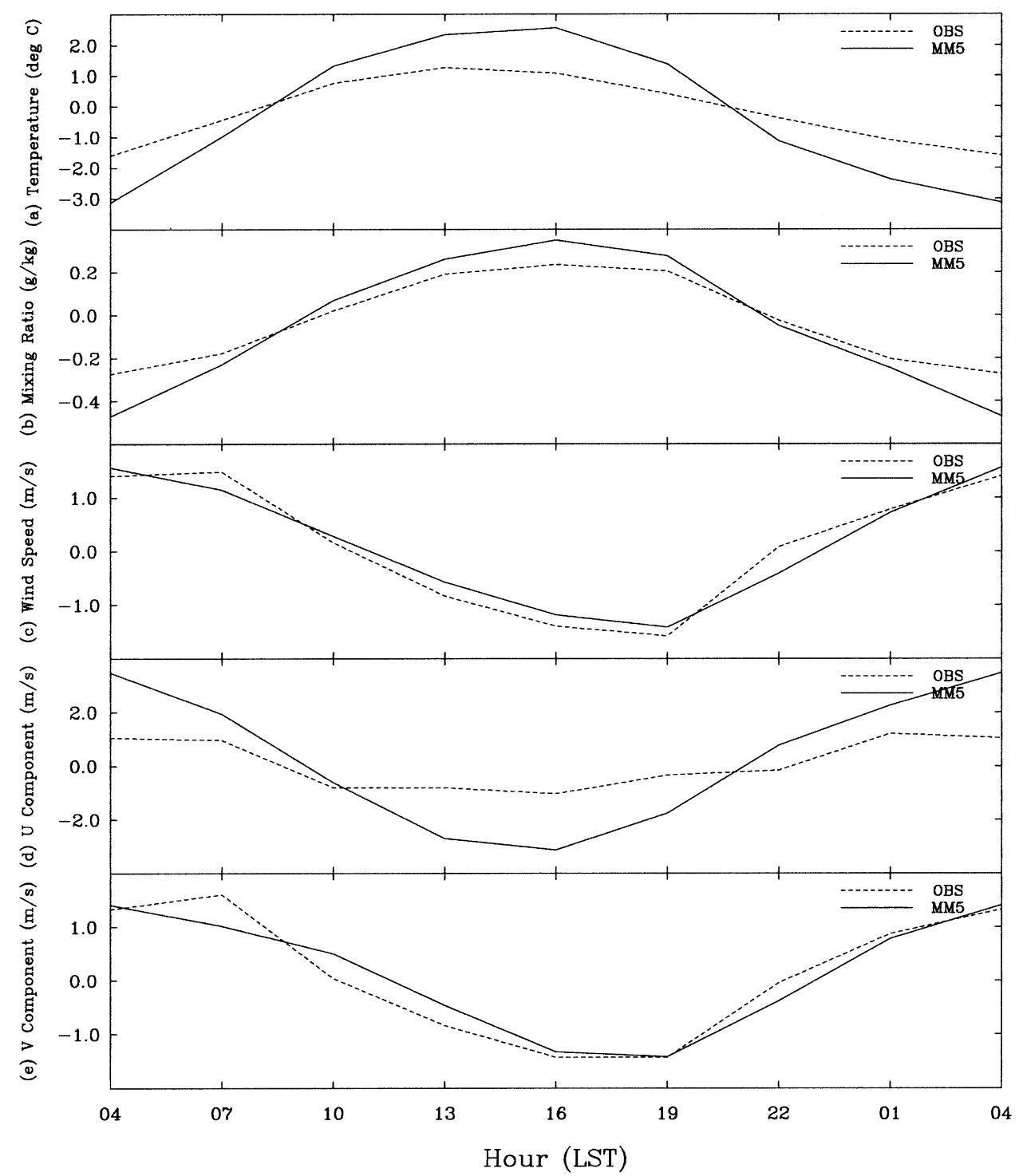

Fig. 23. Average diurnal cycle calculated from the Polar MM5 simulations (solid lines) and station observations (dotted lines) at Mawson for Jan 1993.

The above evaluation suggests that additional model improvements are required. First, in order to better resolve the vertical temperature structure above $200 \mathrm{hPa}$, and reduce the gravity wave effects on the model performance in simulating the near-surface atmospheric state, the top pressure should be set higher than the 100$\mathrm{hPa}$ level, and other upper boundary condition treatments should be explored. Second, additional improvements in the cloud and radiative parameterization schemes are required.

Additional model evaluation work is required. The current study has focused primarily on evaluation of the atmospheric state and has shown that the Polar MM5 accurately reproduces the observed atmospheric conditions. Further analysis of atmospheric processes is required to confirm that these accurate model simulations are achieved through physically correct mechanisms. Additional evaluation should focus on cloud properties and radiative effects, the surface energy balance and turbulent fluxes, and the boundary layer structure. This evaluation will require a dedicated field program using a combination of surface in situ and remote sensors, airborne observation platforms, and satellite observations.

Overall, given the skill present in the Polar MM5 simulations over the Antarctic ice sheets the Polar MM5 can be used to study the Antarctic atmospheric circulation and the mass balance of the ice sheet.

Acknowledgments. This research was funded by National Science Foundation Grants OPP-9725730, OPP9707557, and OPP-9905381, and by National Aeronau- 

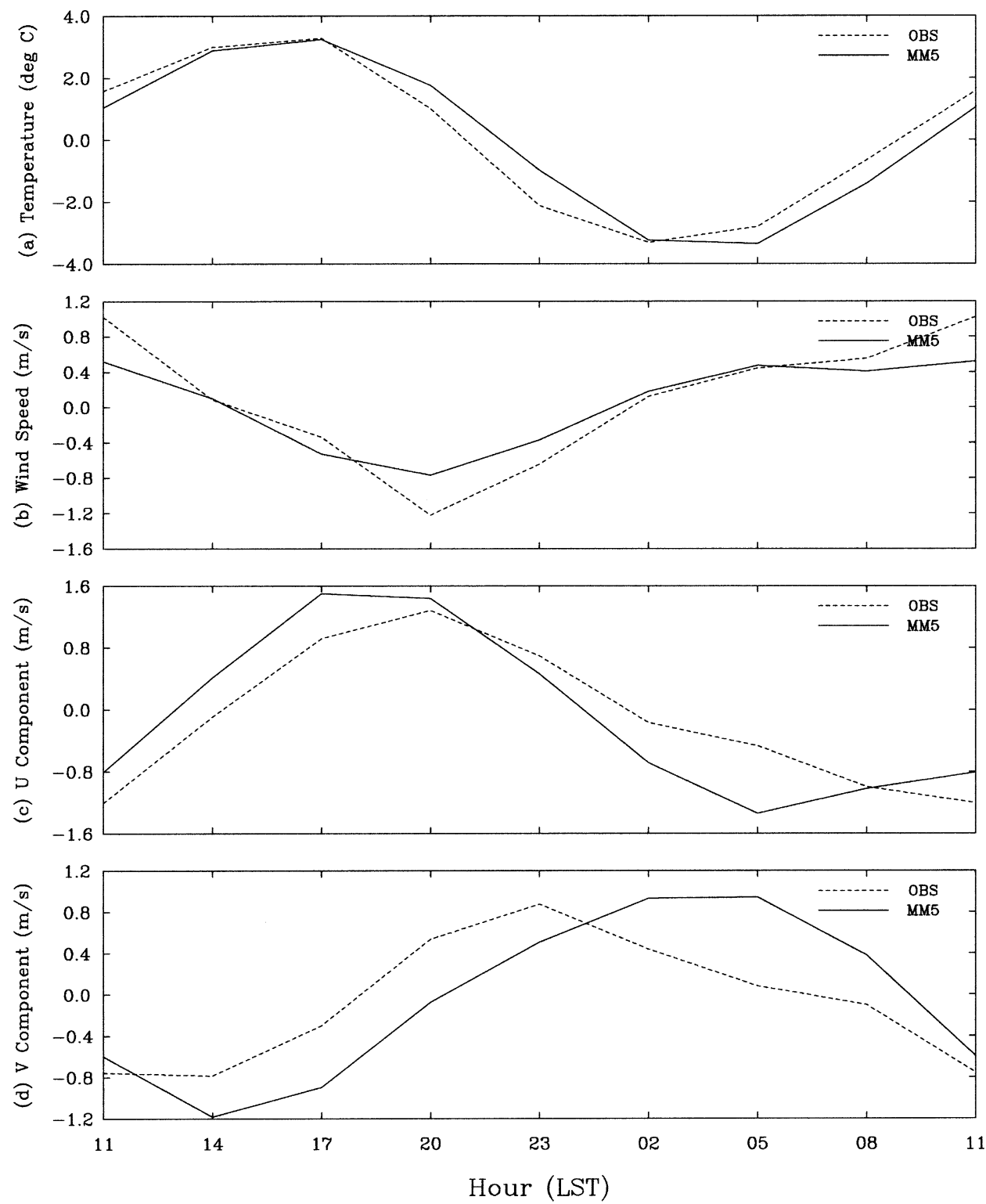

FIG. 24. Average diurnal cycle calculated from the Polar MM5 simulations (solid lines) and station observations (dotted lines) at Sandra for Jan 1993.

tics and Space Administration Grant NAG5-9518, all to D. H. Bromwich. The global ECMWF analyses used in this project were obtained from NCAR under Grant 3706880. Constructive comments from an anonymous reviewer and W. M. Connolley improved the manuscript substantially.

\section{REFERENCES}

Bailey, D. A., and A. H. Lynch, 2000a: Development of an Antarctic regional climate system model. Part I: Sea ice and large-scale circulation. J. Climate, 13, 1337-1350.

$\longrightarrow$, and — 2000b: Development of an Antarctic regional climate system model. Part II: Station validation and surface energy balance. J. Climate, 13, 1351-1361.
Ball, F. K., 1960: Winds over the ice slopes of Antarctica. Ant. Meteor., Pergamon Press, 9-16.

Borisenkov, E. P., and L. V. Dolganov, 1982: Some results of climatic generalization of meteorological observations in the Antarctic. J. Geophys. Res., 87, 9653-9666.

Briegleb, B. P., and D. H. Bromwich, 1998a: Polar radiation budgets of the NCAR CCM3. J. Climate, 11, 1246-1269.

—_ and $-1998 \mathrm{~b}$ : Polar climate simulation of the NCAR CCM3. J. Climate, 11, 1270-1286.

Bromwich, D. H., 1988: Snowfall in high southern latitudes. Rev. Geophys., 26, 149-168.

—_, and T. R. Parish, 1998: Meteorology of the Antarctic. Meteorology of the Southern Hemisphere, Meteor. Monogr., No. 49, Amer. Meteor. Soc., 175-200.

_ _ J. J. Cassano, T. Klein, G. Heinemann, K. M. Hines, K. Steffen, and J. E. Box, 2001: Mesoscale modeling of katabatic winds over Greenland with the Polar MM5. Mon. Wea. Rev., 129, 2290-2309. 
Carleton, A. M., and Y. D. Song, 1997: Synoptic climatology, and intrahemispheric associations, of cold air mesocyclones in the Australasian sector. J. Geophys. Res., 102, 13 873-13 887.

Carrasco, J. F., D. H. Bromwich, and Z. Liu, 1997a: Mesoscale cyclone activity over Antarctica during 1991. 1. Marie Byrd Land. J. Geophys. Res., 102, 13 923-13 937.

$\_, \ldots$, and,$- 1997 \mathrm{~b}$ : Mesoscale cyclone activity over Antarctica during 1991. 2. Near the Antarctic Peninsula. J. Geophys. Res., 102, 13 939-13 954.

Cassano, J. J., J. E. Box, D. H. Bromwich, L. Li, and K. Steffen, 2001a: Verification of polar MM5 simulations of Greenland's atmospheric circulation. J. Geophys. Res., 106, 33 867-33 890.

- T. R. Parish, and J. C. King, 2001b: Evaluation of turbulent surface flux parameterizations for the stable surface layer over Halley, Antarctica. Mon. Wea. Rev., 129, 26-46.

Chen, B., D. H. Bromwich, K. M. Hines, and X. Pan, 1995: Simulations of the 1979-1988 polar climates by global climate models. Ann. Glaciol., 21, 83-90.

Cullather, R. I., D. H. Bromwich, and M. L. Van Woert, 1998: Spatial and temporal variability of Antarctic precipitation from atmospheric methods. J. Climate, 11, 334-368.

Dudhia, J., 1993: A nonhydrostatic version of the Penn State-NCAR Mesoscale Model: Validation tests and simulation of an Atlantic cyclone and cold front. Mon. Wea. Rev., 121, 1493-1513.

Ebert, E. E., and J. A. Curry, 1992: A parameterization of ice cloud optical properties for climate models. J. Geophys. Res., 97, 3831-3836.

Fletcher, N. H., 1962: Physics of Rain Clouds. Cambridge University Press, $386 \mathrm{pp}$.

Giovinetto, M. B., N. M. Waters, and C. R. Bentley, 1990: Dependence of Antarctic surface mass balance on temperature, elevation and distance to open ocean. J. Geophys. Res., 95, $3517-$ 3531 .

Grell, G. L., J. Dudhia, and D. R. Stauffer, 1994: A description of the fifth-generation Penn State/NCAR Mesoscale Model (MM5). NCAR Tech. Note NCAR/TN-398+STR, 117 pp.

Hack, J. J., B. A. Boville, B. P. Briegleb, J. T. Kiehl, P. J. Rasch, and D. L. Williamson, 1993: Description of the NCAR Community Climate Model (CCM2). NCAR Tech. Note NCAR/TN$382+$ STR, 120 pp.

Hahn, C. J., S. G. Warren, and J. London, 1995: The effect of moonlight on observation of cloud cover at night, and application to cloud climatology. J. Climate, 8, 1429-1446.

Heinemann, G., 1999: The KABEG'97 field experiment: An aircraftbased study of katabatic wind dynamics over the Greenland ice sheet. Bound.-Layer Meteor., 93, 75-116.

_, and L. Rose, 1990: Surface energy balance parameterizations of boundary-layer heights and the application of resistance laws near an Antarctic ice shelf front. Bound.-Layer Meteor., 51, 123 158.

Hines, K. M., D. H. Bromwich, and T. R. Parish, 1995: A mesoscale modeling study of the atmospheric circulation of high southern latitudes. Mon. Wea. Rev., 123, 1146-1165.

- D. H. Bromwich, and R. I. Cullather, 1997a: Evaluating moist physics for Antarctic mesoscale simulations. Ann. Glaciol., 25, 282-286.

- - - and Z. Liu, 1997b: Combined global climate model and mesoscale model simulations of Antarctic climate. J. Geophys. Res., 102, 13 747-13 760.

Holmes, R. E., G. A. Weidner, and C. R. Stearns, 1993: Antarctic automatic weather stations: Austral summer 1992-1993. Antarctic J. U.S., 28 (5), 296-299.

Janjić, Z. I., 1994: The step-mountain eta coordinate model: Further developments of the convection, viscous sublayer, and turbulence closure schemes. Mon. Wea. Rev., 122, 927-945.

Kiehl, J. T., J. J. Hack, G. B. Bonan, B. A. Boville, B. P. Briegleb, D. L. Williamson, and P. J. Rasch, 1996: Description of the NCAR Community Climate Model (CCM3). NCAR Tech. Note NCAR/TN-420+STR, 160 pp.
King, J. C., 1990: Some measurements of turbulence over Antarctic ice shelf. Quart. J. Roy. Meteor. Soc., 116, 379-400.

_, and J. Turner, 1997: Antarctic Meteorology and Climatology, Cambridge University Press, $256 \mathrm{pp}$.

Klemp, J. B., and D. R. Durran, 1983: An upper boundary condition permitting internal gravity wave radiation in numerical mesoscale models. Mon. Wea. Rev., 111, 430-444.

Liu, H., K. C. Jezek, and B. Li, 1999: Development of an Antarctic digital elevation model by integrating cartographic and remotely sensed data: A geographic information system based approach. J. Geophys. Res., 104, 23 199-23 213

Manning, K. W., and C. A. Davis, 1997: Verification and sensitivity experiments for the WISP94 MM5 forecasts. Wea. Forecasting, 12, 719-735

Meyers, M. P., P. J. DeMott, and W. R. Cotton, 1992: New primary ice-nucleation parameterizations in an explicit cloud model. $J$. Appl. Meteor., 31, 708-721.

Neff, W. D., 1999: Decadal timescale trends and variability in the tropospheric circulation over the South Pole. J. Geophys. Res., 104, 27 217-27 252.

Parish, T. R., and D. H. Bromwich, 1987: The surface wind field over the Antarctic ice sheets. Nature, 328, 51-54.

, and K. T. Waight, 1987: The forcing of Antarctic katabatic winds. Mon. Wea. Rev., 115, 2214-2226.

— the Antarctic katabatic wind regime. J. Climate, 4, 135-146.

Phillpot, H. R., and J. W. Zillman, 1970: The surface temperature inversion over the Antarctic continent. J. Geophys. Res., 75, 4161-4169.

Pinto, J. O., and J. A. Curry, 1997: Role of radiative transfer in the modeled mesoscale development of summertime arctic stratus. J. Geophys. Res., 102, 13 861-13 872.

Reisner, J., R. M. Rasmussen, and R. T. Bruintjes, 1998: Explicit forecasting of supercooled liquid water in winter storms using the MM5 mesoscale model. Quart. J. Roy. Meteor. Soc., 124, 1071-1107.

Renfrew, I. A., J. C. King, and T. Markus, 2002: Coastal polynyas in the southern Weddell Sea: Variability in the surface energy budget. J. Geophys. Res., 107 (C6), 3063, doi: 10.1029/ 2000JC000720.

Simmonds, I., 1990: Improvements in general-circulation model performance in simulating Antarctic climate. Antarct. Sci., 2, 287 300 .

Stearns, C. R., L. M. Keller, G. A. Weidner, and M. Sievers, 1993: Monthly mean climatic data for Antarctic automatic weather stations. Antarctic Meteorology and Climatology: Studies Based on Automatic Weather Stations, D. H. Bromwich and C. R Stearns, Eds., Antarctic Research Series, Vol. 61, Amer. Geophys. Union, 1-21.

Stull, R. B., 1988: An Introduction to Boundary Layer Meteorology. Kluwer Academic, 666 pp.

Turner, J., and J. P. Thomas, 1994: Summer-season mesoscale cyclones in the Bellingshausen-Weddell region of the Antarctic and links with the synoptic-scale environment. Int. J. Climatol., 14, 871-894

— Study of the Troposphere (FROST) project. Bull. Amer. Meteor Soc., 77, 2007-2032.

_ - S. Leonard, G. J. Marshall, M. Pook, L. Cowled, R. Jardine, S. Pendlebury, and N. Adams, 1999: An assessment of operational Antarctic analyses based on data from the FROST project. Wea. Forecasting, 14, 817-834.

Tzeng, R. Y., D. H. Bromwich, T. R. Parish, and B. Chen, 1994: NCAR CCM2 simulation of the modern Antarctic climate. $J$. Geophys. Res., 99, 23 131-23 148.

van den Broeke, M. R., 1996: The atmospheric boundary layer over ice sheets and glaciers. Ph.D. thesis, University of Utrecht, 178 pp.

1997: Spatial and temporal variation of sublimation on Ant- 
arctica: Results of a high-resolution general circulation model. J. Geophys. Res., 102, 29 765-29 777.

van Lipzig, N. P. M., E. van Meijgaard, and J. Oerlemans, 1999:

Evaluation of a regional atmospheric model using measurements of surface heat exchange processes from a site in Antarctica. Mon. Wea. Rev., 127, 1994-2011.

Vaughan, D. G., J. L. Bamber, M. Giovinetto, J. Russell, and A. P. R. Cooper, 1999: Reassessment of net surface mass balance in Antarctica. J. Climate, 12, 933-946.

Walsh, K., and J. L. McGregor, 1996: Simulations of Antarctic climate using a limited area model. J. Geophys. Res., 101, 19 093-19 108.
Wendler, G., N. Ishikawa, and Y. Kodama, 1988: The heat balance of the icy slope of Adelie Land, eastern Antarctica. J. Appl. Meteor., 27, 52-65.

Xu, J. S., H. von Storch, and H. van Loon, 1990: The performance of four spectral GCMs in the Southern Hemisphere: The January and July climatology and the semiannual wave. J. Climate, 3, $53-70$.

Yen, Y. C., 1981: Review of thermal properties of snow, ice and sea ice. CRREL Rep. 81-10, Cold Regions Research and Engineering Laboratory, Hanover, NH, 27 pp.

Yoshiki, M., and K. Sato, 2000: A statistical study of gravity waves in the polar regions based on operational radiosonde data. $J$. Geophys. Res., 105, 17 995-18 011. 